Illinois State University

ISU ReD: Research and eData

Theses and Dissertations

$4-2-2020$

\title{
Identity Centrality's Influence on the Relation Between Disclosure and Mental Health Stigma
}

Samantha Ege

Illinois State University, samanthamege@gmail.com

Follow this and additional works at: https://ir.library.illinoisstate.edu/etd

Part of the Clinical Psychology Commons

\section{Recommended Citation}

Ege, Samantha, "Identity Centrality's Influence on the Relation Between Disclosure and Mental Health Stigma" (2020). Theses and Dissertations. 1242.

https://ir.library.illinoisstate.edu/etd/1242

This Thesis is brought to you for free and open access by ISU ReD: Research and eData. It has been accepted for inclusion in Theses and Dissertations by an authorized administrator of ISU ReD: Research and eData. For more information, please contact ISUReD@ilstu.edu. 


\title{
IDENTITY CENTRALITY'S INFLUENCE ON THE RELATION BETWEEN \\ DISCLOSURE AND MENTAL HEALTH STIGMA
}

\author{
Samantha Ege
}

\section{Pages}

Past research has shown that disclosing one's mental illness to another individual has reduced one's feelings of self-stigma. However, there are gaps concerning the reasons why the act of disclosing for some decreases self-stigma, whereas the act of disclosing increases selfstigma in others. This study purported to fill this gap by investigating the influence of identity centrality on the relation between disclosure and self-stigma and positive regard's moderation of identity centrality’s influence. Students from Illinois State University were recruited through email and SONA and were asked to complete a series of questionnaires regarding distress, disclosure, identity, positive affect, and self-stigma. Multiple regression analyses were conducted to investigate the influence of identity centrality on the relation between disclosure and selfstigma, as well as the influence of positive regard on identity centrality's moderating relation with disclosure and self-stigma. Identity centrality and positive regard were found to moderate the relation between disclosure and self-stigma. The hypotheses were supported as results showed the hypothesized model was statistically significant: participants who held their mental health diagnosis or distress close to their identity and had high positive regard for it, were more likely to disclose and decrease their self-stigma. However, disclosure of participants who held their mental health diagnosis or distress close to their identity led to higher self-stigma when they held low positive regard toward it. 
KEYWORDS: mental health stigma; self-stigma; identity; coming-out; disclosure 


\title{
IDENTITY CENTRALITY'S INFLUENCE ON THE RELATION BETWEEN DISCLOSURE AND MENTAL HEALTH STIGMA
}

\section{SAMANTHA EGE}

\author{
A Thesis Submitted in Partial \\ Fulfillment of the Requirements \\ for the Degree of \\ MASTER OF SCIENCE \\ Department of Psychology \\ ILLINOIS STATE UNIVERSITY
}


Copyright 2020 Samantha Ege 


\section{IDENTITY CENTRALITY'S INFLUENCE ON THE RELATION BETWEEN \\ DISCLOSURE AND MENTAL HEALTH STIGMA}

SAMANTHA EGE

COMMITTEE MEMBERS:

Daniel G. Lannin, Chair

Matthew Hesson-McInnis 


\section{ACKNOWLEDGMENTS}

This study would not be possible without the assistance from Dr. Daniel Lannin for guiding me through this process, from discussing the current gaps in mental health stigma research, to conceptualizing the study in its entirety. I am grateful for how supportive and informative my thesis committee has been, including Dr. Daniel Lannin and Dr. Matthew Hesson-McInnis; thank you all for allowing me to explore this process with independence and for always being willing to help me when I felt stuck. Their guidance taught me confidence and abstract thinking regarding study conceptualization, and I will use the skills I've learned while furthering my career. I would like to thank my parents for providing tremendous support and encouragement through my academic career and personal life. Without my parents' guidance and honesty, I wouldn't have an interest and passion for those who cope with mental illness. I commend them for their personal strength and openness regarding their own journey with mental health concerns, as well as their support and encouragement for others who cope as well. To all of those who have helped me through this process who I have not named specifically, I thank you for your support and encouragement. Finally, to all of those coping with mental health concerns right now, I thank you for continuing to get up everyday and face the challenge; you are so much stronger than you know.

S.E. 


\section{CONTENTS}

Page

ACKNOWLEDGMENTS

CONTENTS

TABLES

FIGURES

CHAPTER I: PRESENT LITERATURE 1

Mental Health Stigma $\quad 2$

Efforts to Reduce Mental Health Stigma $\quad 6$

Reducing Self-stigma by Identifying with One's Mental Illness and "Coming Out" 8

Centrality of Mental Illness to Identity 11

Mental Health, Identity, and Disclosure $\quad 12$

$\begin{array}{ll}\text { Present Study } & 13\end{array}$

CHAPTER II: METHOD 16

$\begin{array}{ll}\text { Study Design } & 16\end{array}$

$\begin{array}{ll}\text { Participants } & 16\end{array}$

$\begin{array}{ll}\text { Power Analysis } & 16\end{array}$

$\begin{array}{ll}\text { Measures } & 17\end{array}$

$\begin{array}{ll}\text { Distress } & 17\end{array}$

$\begin{array}{ll}\text { Disclosure of Mental Illness } & 18\end{array}$

$\begin{array}{ll}\text { Identity Centrality of Mental Illness } & 19\end{array}$

$\begin{array}{ll}\text { Positive Regard toward those with Mental Illness } & 20\end{array}$

$\begin{array}{ll}\text { Self-stigma } & 20\end{array}$ 
Procedure

Analytical Plan

$\begin{array}{ll}\text { CHAPTER III: RESULTS } & 25\end{array}$

$\begin{array}{ll}\text { Descriptive Analysis } & 26\end{array}$

$\begin{array}{ll}\text { Main Analysis } & 27\end{array}$

Exploratory Analyses of Minoritized Group Differences $\quad 29$

$\begin{array}{ll}\text { CHAPTER IV: DISCUSSION } & 37\end{array}$

Mental Health Stigma and Minoritized Groups $\quad 40$

$\begin{array}{ll}\text { Implications } & 41\end{array}$

$\begin{array}{ll}\text { Limitations and Future Directions } & 46\end{array}$

$\begin{array}{ll}\text { Conclusion } & 50\end{array}$

$\begin{array}{ll}\text { REFERENCES } & 51\end{array}$ 


\section{TABLES}

Table $\quad$ Page

1. Bivariate Correlations and Descriptive Statistics 26

2. Means and Standard Deviations Across Racial \& Ethnic Identities 30

3. Mean Differences Regarding Gender Identity 32

4. Mean Differences Regarding Sexual Orientation 33

5. Mean Differences Regarding Identity Intersectionality 36 


\section{FIGURES}

Figure

Page

1. Mental Health Stigma Depicted Through Public- and Self-stigma 4

2. Original Model of the Relation Between Disclosure and Self-stigma 14

3. Present Study Model of Identity Centrality's Moderating Influence on the Relation

Between Disclosure and Self-stigma, and Positive Regard's Moderating Identity

Centrality's Moderation of the Relation Between Disclosure and Delf-stigma

4. Original Model of the Relation Between Disclosure and Self-stigma and Supporting Correlation

5. Hypothesized Moderated Moderation Model

6. The Hypothesized Moderated Moderation Model's Regression Analysis 


\section{CHAPTER I: PRESENT LITERATURE}

Mental health stigma is a prevalent problem for many individuals who cope with mental illness because it demoralizes them and lowers self-esteem (Cremonini, Pagnucci, Giacometti, \& Rubbi, 2018). People experience mental health stigma from their peers but may also stigmatize themselves (Corrigan, 2004; Vogel et al., 2013). Stigma associated with having a mental illness is a large-scale problem, given that approximately $20 \%$ of the United States' population copes with mental illness (National Institute of Mental Health, 2017). Mental illness appears in a variety of cultures and countries and manifests itself in a multitude of ways, and mental illness can affect any individual regardless of one's nationality, ethnicity, gender identity, biological sex, or sexual orientation (Alonso et al., 2008; Dietrich et al., 2010).

Media influence, social learning, and psychological attribution theory explain the origins of mental health stigma and its reinforcement. Anti-stigma campaigns have sought to reduce stigma by focusing on influencing the development of mental health stigma (Mendenhall \& Frauenholtz, 2013). These campaigns have targeted media portrayal of those who cope with mental illness, mental health literacy, and bringing in an individual who copes with mental illness to disclose the experience associated with the mental illness and the repercussions that those who cope with mental illness usually encounter. Those who cope with mental illness may fail to disclose their struggles due to the threat of marginalization (Link, Cullen, Struening, Shrout, \& Dohrewend, 1989). Furthermore, the identifying characteristic of being someone who copes with a mental illness, or colloquially, someone who is "mentally ill", leads to a negative self perception both socially and intrapersonally (Lally, 1989; Smith, 2007). There is support for the idea of "coming out proud" with one's condition, as it has been shown to decrease mental health stigma and to increase one's self-esteem (e.g., Corrigan et al., 2013a). 
For those with mental illness, hiding their mental illness status to protect themselves from stigma may be untenable — especially because it may be difficult to seek treatment and support for one's mental illness without disclosing one's mental illness. This phenomenon suggests that it may be important to better understand the effects of disclosing one's mental illness on perceptions of stigmatization. Therefore, the researcher purported to expand the previous research surrounding the relations between disclosing one's mental illness and self-stigma, specifically the influence of identity centrality on this relation, and positive regard's moderating influence on this relation (cf. Cremonini et al., 2018). The literature has shown that disclosing one's mental illness is linked to lower levels of mental health stigma, but the aspects of peoples' identity that may influence this relation has not been empirically examined (Corrigan et al., 2010). Understanding how salient aspects of identity influence mental health stigma may provide insight into strategic ways to mitigate the negative effects of stigma. Disclosing one's mental illness may decrease one's self-stigma, but this depends on how central the mental illness is to the individual's identity and the emotions associated with the condition, which is what the researcher strived to investigate.

\section{Mental Health Stigma}

Mental health stigma corresponds to the negative thoughts, feelings, and behaviors regarding someone coping with mental illness (Cremonini et al., 2018). Mental health stigma is multifaceted (Cummings et al., 2013) and may involve at least four attributes: distinguishing people who cope with mental illness, categorizing these people as separate from society, associating these people with a negative connotation, and attributing them to the cause of their condition (Smith, 2007). The first attribute describes the action of separating people into groups, those who cope with or "have" mental illness and those who do not cope with or do not "have" 
mental illness, thus creating an in-group and a designated out-group, categorizing these people as separate from society (Smith, 2007). Similar to many in-group-out-group dilemmas, associating the out-group with a negative connotation or negative characteristics is the action of stereotyping the group of individuals as a negative aspect of the society who thus need to be removed before any further societal damage is done (Smith, 2007). Finally, the fourth attribute of attributing those who cope with mental illness as the cause of their condition. This attribution results in placing blame on these people under the false belief that they are choosing to dysfunction in society and struggle for attention, or other malicious intentions (Smith, 2007). These four attributes are important to understanding how mental health stigma manifests itself in society as well as those who cope with mental illness.

Mental health stigma is conceptualized as reflecting both public stigma and self-stigma. Public stigma corresponds to peer and societal stigma directed toward individuals who cope with mental illness, whereas self-stigma corresponds to the internalization and application of that stigma toward one's self when coping with a mental illness (Corrigan, 2004; Vogel et al., 2013). For example, an individual who copes with mental illness not being hired by an employer due to a diagnosis is an example of public stigma. Consequentially, this individual may hold negative feelings about the experience and have thoughts like, 'I'm never going to get a job, I'm useless; no one wants me"; this is an example of self-stigma. Due to disclosure being an individual choice and experience, self-stigma is the only aspect of stigma that is being measured in this present study.

Both public stigma and self-stigma reflect a multifaceted construct that includes stereotypes, prejudice, and discrimination toward individuals who cope with mental illness (Cremonini et al., 2018), as can be seen in Figure 1. The upheld stereotypes, prejudices, and 
discriminatory actions that correspond with mental health stigma can create detrimental consequences for those who cope with mental illness (Cremonini et al., 2018). These include, but are not limited to, poverty, unemployment, criminalization, and social intolerance. Other consequences include depression and societal marginalization, whether in the form of social withdrawal from the individual's self-stigma or from public stigma (Dumesnil \& Verger, 2009; Lysaker et al., 2006; Quinn et al., 2014).

Figure 1

Mental Health Stigma Depicted Through Public-and Self-stigma

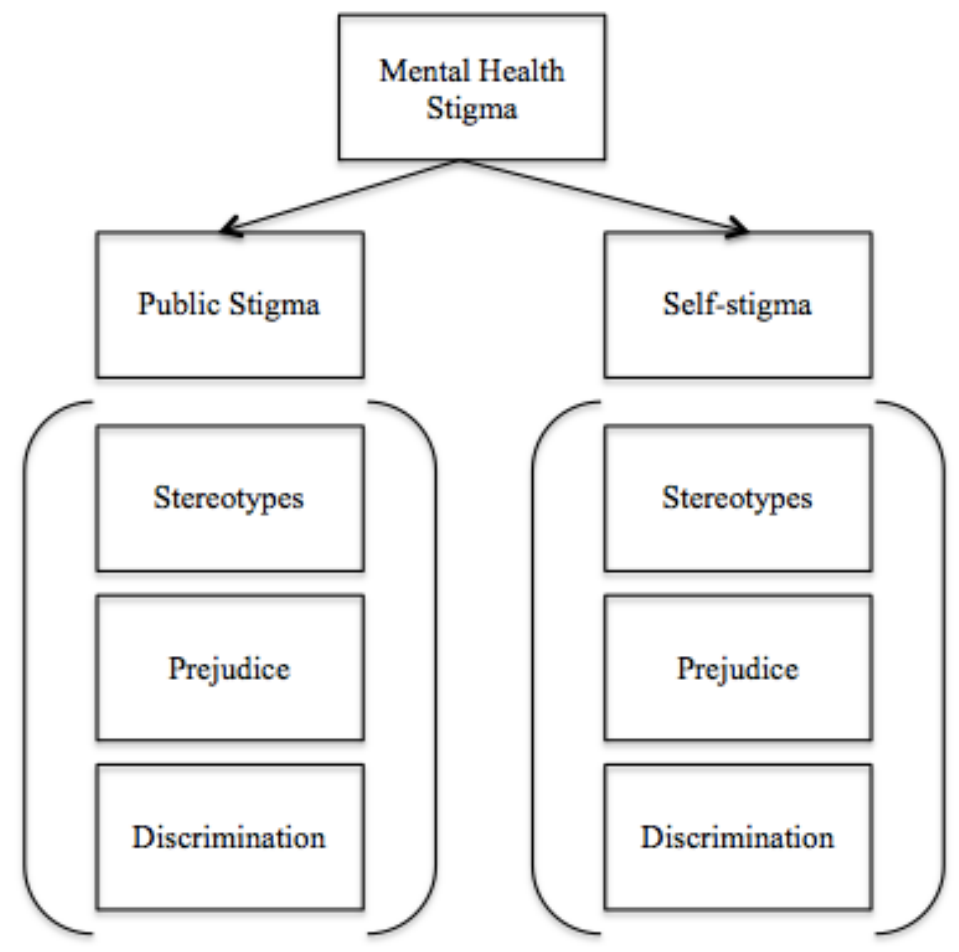

Stereotypes of those with mental illness include, but are not limited to, being the caused of their condition, incompetency, and unpredictability/uncontrollability. Stereotypes are linked to prejudice or the negative connotation attributed to a specific group, in this case those who cope with mental illness (O’Driscoll et al., 2012). Clark and colleagues found that controllable behavior is less stigmatized than spontaneous behavior; in other words, those who cope with 
mental illness are uncontrollable and therefore are a threat and need to be separate from society (2013). Along with unpredictability, those who cope with mental illness are seen as violent and dangerous, a stereotype that has increased in recent years (Thornicroft et al., 2015). Cremonini and colleagues found that violent stereotypes reinforce the prejudice against those who cope with mental illness (2018). These stereotypes are not accurate for the entire population of people who cope with mental illness; these stereotypes hinder mental health literacy (i.e. knowledge and applications of mental health resources; Clark et al, 2013). These stereotypes originate from a multitude of sources, including media, learned beliefs, as well as misinformation about mental illness, which then become internalized by those who cope with mental illness (Link et al., 1989, Vogel et al., 2013).

Prejudice and discrimination can hinder mental health literacy and psychoeducation (Skre et al., 2013). An example of prejudice in the lens of public stigma could look like a family feeling unsafe when a group home for those who cope with severe mental illness is established in their community, resulting in avoidance behavior. Through the lens of self-stigma, one who copes with mental illness may think of himself as unworthy of love or acceptance due to his condition, resulting in low self-esteem.

When an individual believes the stereotypes, prejudice, and discrimination that society directs toward those who cope with mental illness, and applies those beliefs toward himself, this is referred to as self-stigma (Cremonini et al., 2018). Those who cope with mental illness tend to cast blame on themselves for their condition, as if their character caused their mental illness; for example, an individual blaming himself may think, "I'm a lost cause, I'm worthless, why would anyone want to help me or be with me" (Mak \& Wu, 2006). Corrigan has termed this feeling of helplessness or being a lost cause the "why try effect" (Corrigan et al., 2009). These individuals 
may often try to hide their condition from others and "pass" as a "normal" individual (Lally, 1989).

\section{Efforts to Reduce Mental Health Stigma}

Research has shown that education and contact with those who cope with mental illness are the two fundamental approaches to anti-stigma campaigns (Corrigan et al., 2015). Education has been associated with decreasing mental health stigma (Omori et al., 2012). Education includes mental health literacy, whereas the lack of mental health literacy is associated with the origins of mental health stigma. Mental health literacy is the knowledge and understanding of mental health resources as well as mental illness symptoms and signs (Mendenhall \& Frauenholtz, 2013). The mental health resources include mental health first aid, or the steps to help someone who is struggling with a mental illness, such as referring the individual to a clinical counselor, psychiatrist, even a general practitioner (Melas et al., 2013; Jorm, 2015). Learning proper mental health first aid has been associated with an increase in mental health literacy (Kitchener \& Jorm, 2006). On the other side of this statement, a deficit in mental health first aid can contribute to the decrease or overall lack of mental health literacy. Perry and colleagues reported that there has been a societal decline in mental health literacy over time (2014).

Examples of initiatives to promote mental health literacy include Beyondblue, Open the Doors, Breaking the Silence, Minds Like Mine, and the Adolescent Depression Awareness Program; these programs have had significant short-term effects on the increase of mental health literacy and a significant decrease of mental health stigma (Gaebel \& Baumann, 2003; Reavely \& Jorm, 2012; Sartorious, 2010; Swartz et al., 2010; Swartz et al., 2017; Thornicroft et al., 2015; Weisman et al., 2016; Zhuang et al., 2017). The literature concerning the effectiveness of these 
anti-stigma campaigns has concluded that anti-stigma campaigns should be multifaceted, multidimensional, and catered to specific individuals. Group education sessions have been found to be more effective in reducing mental health stigma as well (Boysen \& Vogel, 2008; PintoFoltz et al., 2011; Thornicroft et al., 2015). For example, primary schools have successfully created interactions with those who cope with mental illness and have added prevention, education, help-seeking behaviors, and effective coping strategies in their curriculum (Smith \& Applegate, 2018; Swartz et al., 2013; Tay et al., 2018).

Furthermore, contact with those who cope with mental illness has been found to reduce mental health stigma, even more so than education (Corrigan et al., 2015; Sebastian et al., 2017). Interpersonal contact with someone who copes with mental illness is known as the contact hypothesis; the contact hypothesis has been shown to elicit empathy in individuals as well as the humanization of the person who copes with a mental illness, depending on the sample (Cremonini et al., 2018; Dietrich et al., 2010; Pinto-Foltz et al., 2011). The main premise of the contact hypothesis is that one's disclosure is used as a tool to humanize the marginalized group, those who cope with mental illness. Disclosure is the process of sharing one's experience, in this case one's mental health diagnosis, with another individual, whether that is a parent, friend, family member, counselor, or peer. To deescalate the tension in this specific in-group-out-group dilemma, Pinto-Foltz and colleagues found that contact with both groups under circumstances such as equality, support, and on common ground, can reduce this conflict and reduce stigma, however these environments seldom exist in research or society (2011).

Advocates for people with mental illness have focused efforts on anti-stigma campaigns that emphasize debunking the myths and stereotypes of those who cope with mental illness (Sebastian \& Richards, 2017). Being an ally to those who cope with mental illness has been 
effective in reducing mental health stigma; however, those who personally cope with mental illness can have a more active role in decreasing mental health stigma. Corrigan has stated that allowing those who cope with mental illness to help themselves can elicit their own autonomy, thus humanizing them (2005). For example, Corrigan presents the potential benefits from those who cope with mental illness to disclose their conditions to others (2005).

\section{Reducing Self-stigma by Identifying with One's Mental Illness and "Coming Out"}

Hiding one's mental illness may worsen the symptoms and ostracize the individual due to his own social withdrawal. However, when others are aware of an individual's illness such as peers, family members, or future employers, it heightens the risk of social marginalization and belittlement of the individual's identity and humanness as a whole (Quinn \& Chaudoir, 2009). This social withdrawal can hinder peers from assisting the individual or instill a sense of helplessness in the individual, himself (Rudick \& Dannels, 2018; Stull et al., 2013). Therefore, it may be important for empirical research to examine the moderating factors that influence the effect of disclosing one's mental illness on subsequent self-stigmatization.

If an individual's mental illness is salient and central to his identity, then the feelings of inadequacy stemming from the illness's negative connotations can be even more detrimental to the individual's self-esteem. Individuals who cope with mental illness and who see their illness as more central to themselves tend to anticipate stigma from others, thus compromising their own self-esteem and psychological wellbeing (Quinn \& Chaudoir, 2009). Lysaker and colleagues (2007) found that the decrease in self-stigma alleviates symptoms related to the mental illness, making the illness more manageable and allowing for more efficient coping. Selfstigma has been seen to be the primary contributor to the quality of life among a variety of psychological assessments of various psychological constructs; in other words, it has been 
empirically supported that self-stigma holds a strong negative correlation with quality of life (Corrigan, Sokol, Rüsch, 2013b).

Research among the LGBTQIA+ populations may give insight into how disclosure can affect one's emotions regarding their diagnosis or social label: namely, the process of "coming out" (Corrigan et al., 2010). Interestingly, the notion of "coming out proud" may potentially alleviate the severity of mental health self-stigma (Corrigan et al., 2010). In other words, some individuals may tend to assign themselves with fewer demoralizing stereotypes and prejudicial beliefs if they disclose their mental illness in a manner that emphasizes their dignity and pride. "Coming out" is a term that has become generalized to other contexts but originally referred to the acknowledgment of one's sexual orientation to oneself and to one's peers, friends, family, acquaintances, etc. (Morrow, 1996).

According to Quinn and colleagues, identity internalization, identity centrality, salience, and "outness" of a person's culturally undesirable identity can contribute to expected stigma (2014). One's identity is associated with one's group identity; when someone identifies as a part of a specific group, it is termed their "in-group". Identifying with a group is termed, "group identification". Identifying with a group is when an individual connects or has an attachment to a certain group, known as the in-group (Corrigan et al., 2013b). This idea has been associated with an improved perceived quality of life because it can be a coping technique regarding discrimination or prejudice towards the in-group (Corrigan et al., 2013b; Corrigan et al., 2010). In regards to mental illness, if someone identifies with others who cope with mental illness, it may provide a support system and an increase in self-esteem and quality of life.

Providing a support system for those who cope with mental illness, which includes disclosure of one's condition in and of itself, emphasizes a sense of protection of one's own 
group. Social Identity Theory states that the group is motivated to maintain a desirable and "distinct social identity" (Kachanoff et al., 2016). Group mentality emphasizes protecting those in the in-group to maintain strong group ties; one must associate themselves as a group member, as well as incorporating the group into the individual's identity to protect his social ties to the group and the group's protection. An individual's identity and identity stability can affect one's self-esteem. One's recognition of or agreement with the stereotypes applied to the in-group, and by extension the individual, could diminish one's self-esteem, even if the group is supportive (Corrigan et al., 2010). Following this idea, if an individual identifies with a specific group, or has high identity centrality regarding those who cope with mental illness, depending on the amount of positive regard, then the individual's self-esteem could improve. Positive regard is the positive emotions associated with a group of people or a characteristic; if an individual holds minimal or no positive regard for others who cope with mental illness or mental illness itself, the individual could refuse to continue to disclose his condition or disclose with shame and guilt about his condition, presenting mental illness as shameful and disgraceful.

Furthermore, certain constructs dictate a group's effects on an individual's psychological wellbeing. One construct is saliency, or the concept of stability in one's self-perception and behavior. Salience is contextual and is dependent on the willingness of the individual to integrate a certain characteristic or group to his identity (Sellers et al., 1997). Regarding mental illness, if an individual perceives his characteristics like those who cope with mental illness, that individual may be more willing to associate with others who cope with mental illness, increasing identity centrality. If the individual does not, then he would have low identity centrality to those who cope with mental illness. Public regard is when individuals view the group a certain way, whereas private regard is an individual's view of one's own membership in a group. Positive 
regard mirrors public- and self-stigma but directed towards identity regarding an in-group or outgroup (Settles, 2004). Positive regard therefore could affect one's identity, specifically to those who cope with mental illness, and therefore should be considered when discussing identity when an individual discloses his condition.

\section{Centrality of Mental Illness to Identity}

The extent to which one's mental illness is central to one's identity may be especially relevant in predicting whether one experiences self-stigma and is willing to disclose his mental illness to others. Bry and colleagues (2017) found that sexual orientation is integrated into one's identity through the process of coming out. Integrating something into one's identity coincides with the processes of self-acceptance and disclosure of one's characteristic. Coming out, verbally, is associated with improved psychological wellbeing (Bry et al., 2017; Villicana et al., 2016). Addressing the negative feelings that may result from being marginalized from society with self-acceptance can alleviate the negative feelings, themselves. Psychological wellbeing is related to mental health concerns; Bry and colleagues (2017) found that disclosure negatively correlates with mental health problems, implying that disclosure improves one's psychological wellbeing (Villicana et al., 2016). Bry and colleagues found that disclosure can either limit or open communication depending on a multitude of factors: seriousness of mental illness, to whom the individual discloses, and in what manner, etc. (2017).

Not only does disclosure of one's sexual orientation affect one's psychological wellbeing but can also affect one's feelings of social support from a group (Villicana et al., 2016). The greater verbal disclosure, among a group, the greater the feeling of social support; coming out can be a way of changing one's self-stigma. Villicana and colleagues found this tendency to be significant with the LGBTQIA+ community (2016). In other words, disclosing one's identity 
with pride may allow for unhealthy relationships to dwindle and allow healthier relationships to take place due to the increase in self-acceptance. Corrigan and colleagues suggested that the LGBTQIA+ community shared similar social marginalization experiences to those who cope with serious mental illness, thus the information found from previous research with the LGBTQIA+ community might apply to mental health research (2010). The literature thoroughly describes the relation between disclosure and self-stigma related to one's sexual orientation, as well as the identity integration process for those in the LBGTQIA+ community due to the disclosure, colloquially known as the "coming out process". The LBGTQIA+ community and the mental health community share the experience of marginalization; therefore, the relation between disclosure and self-stigma in LBGTQIA+ community members experience might be applied to those who cope with mental illness.

\section{Mental Health, Identity, and Disclosure}

Similar to the process one undergoes when considering coming out about one's sexual orientation, coming out about one's mental illness might also involve weighing the negatives and positives of disclosure, as the way one discloses can dictate the outcome of the experience (Corrigan et al., 2013a). There may be many negative consequences of coming out about mental illness if it is disclosed with a negative and shameful connotation or demeanor. In other words, how one feels about his own mental health diagnosis influences his disclosure, and in turn, influences his own feelings of self-stigma. In modern society, identifying as a person who copes with a mental illness is considered socially undesirable. Self-stigma does not come from the label or the identification of someone who is "mentally ill" but from the perception that the stigma is a threat or observable mark that can expose the individual to harm, either from themselves or from others (Corrigan et al., 2013a). This phenomenon occurs in those who cope with more severe 
mental illness: schizophrenia, personality disorders, obsessive-compulsive disorder (OCD), etc. Corrigan found that hostility and blame from family members after an individual discloses his mental illness is called "expressed hostility" (2000). This expressed hostility can reduce one's self-esteem, reinforcing the feelings of helplessness and fear of rejection, which can lead to the individual adopting a "why try" effect, where the individual who copes with a mental illness sees themselves as a patient, one with a terminal diagnosis and detrimental prognosis of his mental illness (Corrigan et al., 2013a). This self-perception may depict a personal need for more assistance or self-awareness of lower functioning (DeTore et al., 2019).

However, disclosure can lead to support from other people who cope with mental illness. Disclosing one's experiences can allow for open communication, leading to possible treatments and increased self-esteem (Corrigan et al., 2013a). Disclosing one's mental illness can decrease self-stigma, and those who cope with mental illness do not have to hide their condition and emphasizes the potential for empowerment through disclosure (Corrigan et al., 2013a). To decrease self-stigma, the disclosure at the individual level should be empowering and proud. Corrigan and colleagues believe that "coming out proud" can have an extensive and positive impact on the self-stigma of those who cope with mental illness (2013a). Following one's disclosure, the group identification aspect of the disclosure connects people and provides social belonging, thus serving as a source of support and buffering against self-stigma (Corrigan et al., 2013a; Corrigan et al., 2013b).

\section{Present Study}

This present study attempts to fill this gap by exploring the influence of identity centrality and positive regard on the relation between disclosure and self-stigma, as shown in Figure 2. 
Figure 2

Original Model of the Relation Between Disclosure and Self-stigma

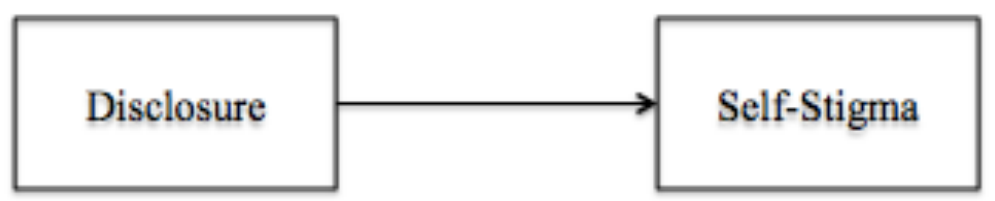

Disclosure is hypothesized to decrease the feelings of self-stigma in some who come out about their mental illness according to research (Corrigan, 2013a). This study purports to replicate Corrigan's results concerning "coming out proud", while disclosure is hypothesized to contribute to the decrease of self-stigma in the original model, as depicted in Figure 2 (Corrigan, 2013a).

Whereas coming out proud may decrease self-stigma for many who disclose their mental illness, it may not decrease the feelings of self-stigma for all who disclose. It is hypothesized that the relation between disclosure and self-stigma will only be shown with the influence of identity centrality as a moderator. If an individual identifies with others who cope with mental illness it would increase the likelihood of disclosing one's mental illness and potentially reduce selfstigma. However, an individual can identify with a group or condition but may not hold positive emotions towards it; therefore, positive regard is hypothesized to moderate the influence of identity centrality on the relation between disclosure and self-stigma, as depicted in Figure 3. 
Figure 3

Present Study Model of Identity Centrality's Moderating Influence on the Relation Between Disclosure and Self-stigma, and Positive Regard's Moderating Identity Centrality's Moderation of the Relation Between Disclosure and Self-stigma

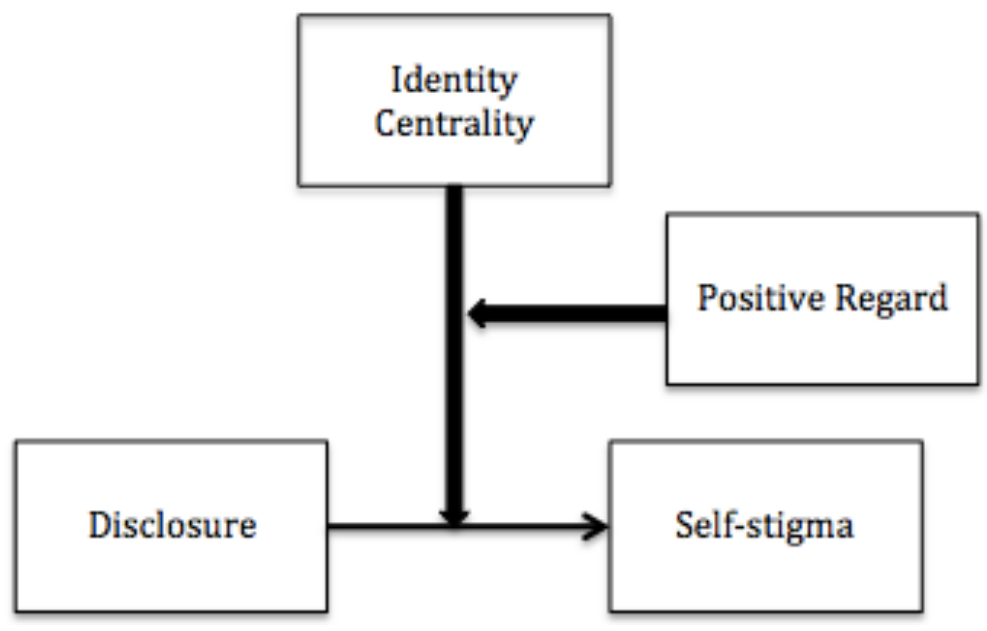

Note: Thicker lines depict moderating effects, while the thinner line depicts the previously supported relation.

For instance, if individuals do not consider their mental illness central to their identity, how they feel about their condition is moot. However, if individuals consider the mental illness central to their identity, then depending on how they feel about their condition, dictates the moderation of their condition being central to their identity. Therefore, it is hypothesized that higher reports of identity centrality and higher reports in positive regard will ultimately lead to less self-stigma, but higher reports in identity centrality and lower reports in positive regard are hypothesized to lead to more self-stigma, through the relation between disclosure and selfstigma. 


\section{CHAPTER II: METHOD}

\section{Study Design}

This cross-sectional, correlational design investigates the relation between disclosure and self-stigma, along with the influence of identity centrality as a moderator, as well as positive regard's influence on identity centrality's moderation.

\section{Participants}

Undergraduate students enrolled in psychology courses at Illinois State University were recruited and compensated via SONA, which is administered by the Psychology Department, and a mass e-mail directed towards those currently enrolled in classes at Illinois State University. Final analyses will include participants reporting severe levels of psychological distress or those who have had a previous mental health diagnosis.

\section{Power Analysis}

The mental health stigma community has established a relation between disclosure and self-stigma (Corrigan, 2013a). Previous studies have not included the impact of one's identity regarding one's mental illness and one's emotions towards it: identity centrality and positive regard. However, Quinn and Chaudior (2009) conducted an experiment including the independent variables centrality and salience, which consisted of 377 participants. Experimenters found significant results indicating that salience and centrality were positively correlated with anticipated public stigma of mental illness (Quinn \& Chaudior, 2009). The experimenters did not report the effect sizes in the article.

Therefore, three power analyses were conducted using a large effect size, a medium effect size, and a moderate effect size (between small and medium effect sizes). The power analyses were conducted on G-Power 3.0.10 software (Erdfelder, Faul, \& Buchner, 1996), and 
specified $F$-tests linear multiple regression: fixed model, $r^{2}$ increase, with a priori: compute required sample size - given $\alpha$, power, and effect size. For the analyses, $\alpha$ error probability was equal to .05 , power was equal to .80 , and the number of tested and total predictors was seven. For the conservative estimate, it was specified effect size as a slightly larger effect (.02), which requires approximately 725 participants to achieve a critical $F$ value of 2.02 , with an actual power equal to .80 . it was specified effect size as a moderate effect size (.08) for the mild estimate, which required approximately 187 participants to achieve a critical $F$ value of 2.06 , with actual power equal to .80 . The liberal estimate, which the effect size was specified as a medium effect (.15) required 103 total participants to achieve a critical $F$ value of 2.12, with actual power equal to .80 . Due to the disparity of these estimates and to balance between achieving sufficient power and understandable limitations of data collection, the mild estimate was sufficient as a guideline for sampling, with a target of 200, which accounted for potential random and extreme response patterns.

\section{Measures}

\section{Distress}

The K6+ Psychological Distress Scale (Kessler et al., 2002) was used to assess psychological distress due to its high reliability and discriminant validity (Kessler et al., 2003). It has been shown that participants who reported mental health needs were statistically significantly different than those who did not report mental health needs, $p<.001$ (Prochaska, Sung, Max, Shi, \& Ong, 2012). The measure consists of six self-report items regarding the participants' mental health, on a scale from 1 to 5,1 being "All the time" and 5 being "None of the time", regarding specific feelings such as “nervous”. Based on the participants' self-reported distress, they were be assigned to one of two groups: not severely distressed, and severely distressed. For 
scoring, items are transformed to a 0 to 4 scale, so that higher scores indicate greater distress. Scores can range from a minimum of 0 to a maximum of 24 . Reliability analyses showed that the Distress Scale showed high reliability, $\alpha=.83$. The overall mean score for the Distress Scale was $11.50(S D=4.504)$, with a variance of 20.29 .

\section{Disclosure of Mental Illness}

Participants were asked if they had a previous diagnosis of a mental health disorder. Along with those who qualified for a mental health disorder diagnosis via the distress scale, those scoring 12 or above, those who indicated being previously diagnosed with a mental health disorder were included in the final analyses. Disclosure of mental illness was measured by an adapted version of the Nebraska Outness Scale, from Meidliner and Hope (2014), which originally measured outness of one's sexual orientation. The Nebraska Outness Scale includes 5 self report rating questions on how "out" a person is about his mental illness, and 5 self report rating questions on how "concealed" a person is about his mental illness. An example of an "out" item is, "What percent of the people in this group do you think are aware of your mental illness (meaning they are aware of your condition, professional diagnosis, struggles, etc.)? Members of your immediate family (e.g. parents and siblings?)" An example of a "concealed" item is, "How often do you avoid talking about topics related to or otherwise indicating your mental illness (e.g. not talking about your symptoms, avoiding social interaction, lying about getting professional psychological help) when interacting with members of these groups? Members of your immediate family (e.g. parents and siblings?)" These questions go from $0 \%$ out $/$ concealed to $100 \%$ out/concealed. An open-ended question will be presented at the end of both the disclosure section and the concealment section to identify the emotional impact of the potential interactions and experiences of disclosure or concealment for each client, for example, "Please 
provide a brief summary on how the interactions with others of whom you have disclosed to went in terms of positive outcomes to negative outcomes when you disclosed your mental illness"? This measure showed high internal reliability, $\alpha=.89$, as well as showing high convergent validity $(r=.84, p<.010)$, discriminant validity $(r=-.45, p<.010)$, and predictive validity $(r=.32, \mathrm{p}<.010$; Meidlinger $\&$ Hope, 2014). These results show that this measure is sufficient for measuring outness and disclosure. The Disclosure of Mental Illness Scale, disclosure section, showed acceptable reliability, $\alpha=.74(M=155.75, S D=93.09)$. The concealment section showed high reliability as well, $\alpha=.87(M=335.06, S D=134.10)$.

\section{Identity Centrality of Mental Illness}

Identity centrality was measured using a modified version of the centrality scale adapted from Sellers et al. (1997). The scale originally measured centrality with the Black community, or how much one identifies as a Black person. Instead of the feelings of centrality with the Black community, the adapted version altered the wording so the community with which respondents identify refers to the community of those who cope with mental illness. The original scale includes eight self-report statements and participants were required to mark how much they believed the statement reflected their identity on a scale from 1 to 9,1 being does not reflect identity, 9 being highly reflects identity. An example of the centrality scale is, "I have a strong sense of belonging to people who cope with mental illness"; this particular statement will be scored using the previously stated scale, however, some statements will be reversed scored; overall only three items are reverse scored. For example, "Being someone who copes with mental illness is unimportant to my sense of what kind of person I am", this statement will be reverse scored. The original measure was found to have high internal consistency $(\alpha=.77)$ and high construct and predictive validity, which suggests that this measure is sufficient for 
measuring identity centrality and therefore was chosen to measure identity centrality of mental illness in the present study (Sellers et al., 1997). The adapted version showed high reliability, similar to the original scale's reliability, $(\alpha=.75)$.

\section{Positive Regard toward those with Mental Illness}

The positive regard scale was modified from Sellers et al. (1997) scale that was originally used to measure positive regard towards the Black community and was found to have adequate internal consistency $(\alpha=.60)$ and high predictive validity and construct validity (Sellers et al., 1997). The scale's high validity shows that this measure was sufficient in measuring positive regard in this study. The adapted version of the positive regard scale was used to measure positive regard towards those who cope with mental illness instead of the Black community. The original scale includes seven self-report statements. Three items were reverse scored, for example, "Overall, I often feel that people who cope with mental illness are not worthwhile". Most items were scored regularly, for example, "I am happy that I cope with a mental illness". The participants will be asked to score how much the statement reflects their identity, 1 being the item does not reflect identity, and 9 being the item highly reflects identity. The adapted version included items one, three, four, six, and seven from the original scale, but removed items two, five, and eight to increase the scale's reliability. Following the item removal, the scale showed improved reliability, $(\alpha=.69)$. The scale's mean score was $32.66(S D=6.94)$.

\section{Self-Stigma}

The Self-Stigma of Mental Illness scale (SSOMI; Tucker, Hammer, Vogel, Bitman, Wade, \& Maier, 2013) which was adapted from Vogel et al. (2006) assessed self-stigma associated with having a mental illness. The scale includes ten self-report statements; participants were asked to mark how much they agree with each statement, on a Likert scale 
from 1 to 5 where $1=$ strongly disagree and $5=$ strongly agree. Higher scores show that the participant holds fewer stigmatizing attitudes towards mental illness. Six items are reversed scored, for example, "I would feel inadequate if I had a mental illness"; four items are scored regularly, for example, "My self-confidence would remain the same if I had a mental illness". This measure showed high convergent validity with the Self-Stigma of Depression Scale, $r=$ $.72, p<.001$ (Tucker et al., 2013). The scale's internal consistency is between .91 and .92 (Tucker et al., 2013). The scale showed exceptionally high reliability, $(\alpha=.90)$. The mean score was $33.02(S D=8.26)$.

\section{Demographics}

Demographic information will include the age, gender identity, sexual orientation, racial/ethnic identity, etc. Demographic information was used to investigate any racial/ethnic, gender, or sexual orientation differences in the sample.

\section{Procedure}

Students from Illinois State University were recruited and compensated through either a mass e-mail or SONA; those who responded via the mass-email and were invited to complete a Qualtrics survey after providing informed consent. Following the informed consent form, students were asked if they were at least 18 years or older and if they would like to continue with the study. An informed consent check was used to screen those who are not 18 years old or older from participating in the study, as well as let individuals opt in or opt out of continuing with the study once the informed consent form has been read. It consisted of two "yes" or "no" questions. An example question is as follows, "Are you 18 years old, or older? Yes, I am at least 18 years old, or No, I am not 18 years old (17 years old or younger)". Following this, the Distress scale was presented first to measure the participant's degree of psychological distress. According to 
the participant's score, if the score is above 12 , then the participant was assumed to cope with a mental illness, as the distress reported qualifies for a mental health diagnosis, diagnosed or undiagnosed (Kessler et al, 2003).

Following the Distress Scale, participants were presented with the Disclosure Scale, and were asked to rate each percentile of those who they have disclosed to, regarding their mental health diagnosis or psychological distress. Participants were then asked to describe the disclosure and indicate positive or negative experiences. Then, participants completed the Identity Centrality Scale, the Positive Regard Scale, and the Self-Stigma Scale. Following the SelfStigma Scale, participants were asked directly if they have ever been diagnosed with a mental illness, yes, no, or prefer not to answer. Participants were then asked to indicate whether or not they have disclosed their mental health diagnosis or psychological distress to anyone, yes, not, or prefer not to answer.

Participants then completed the demographic information, which included age, gender identity, sexual orientation, year in school, international student status, and race/ethnicity identity. After completing the demographic information, participants were presented with a debriefing statement online, which illuminated the full purpose of the study and what we measured, along with reiterating the participants' confidentiality and contact information if the participant had questions about the study. The participants who were recruited from the mass email were shown a Contact Information Option, which asked whether or not they would like to provide their contact information to be entered in a raffle for a \$25 Amazon gift card. This section of the survey came after the individual had read the debriefing statement, only shown to those who responded to the mass e-mail recruitment method. The participant was asked whether or not he wished to give the researcher his contact information (name and e-mail address) so that 
he would be placed in a raffle for a $\$ 25$ Amazon gift card. There was one question asking the participant whether or not he wanted to be directed to another Qualtrics survey, which would not connect his contact information with his responses. The participant could either select a "Yes" option or a "No" option. Those who were recruited via SONA were granted SONA credit.

\section{Analytical Plan}

Multiple regression analyses were conducted, and those who had disclosed their mental illness will be compared to those who had not disclosed their mental illness in SPSS 25 utilizing Hayes (2017) PROCESS model. Analyzing the correlation between disclosure and self-stigma through the regression analysis was used to support past literature in establishing a relation between disclosure and self-stigma. Further regression analysis included identity centrality as a moderating variable, regarding the relation between disclosure and self-stigma. Finally, positive regard was included in the third regression analysis, as a moderating variable for the influence of identity centrality on the relation between disclosure and self-stigma.

Correlations were analyzed through the regression analysis and were used to support the hypothesis that states that higher scores in identity centrality and higher scores in positive regard would influence the relation between disclosure and self-stigma and leading to less self-stigma. The same analysis was used to support the hypothesis that states, higher scores in identity centrality and lower scores in positive regard were hypothesized to impact the relation of disclosure and self-stigma, leading to more self-stigma.

Further analyses was conducted regarding the statistically significant differences regarding the participants' gender identity, sexual orientation, and racial/ethnic identity. Exploratory analyses were conducted following the demographic analyses to expand on the 
proposed model, in comparison to Corrigan's eluded model (2013), to expand the literature in an efficient way. 


\section{CHAPTER III: RESULTS}

One thousand and seventy-four individuals responded to the recruitment e-mail and SONA; 202 individuals indicated being severely distressed as their distress scale scores were over 12 (cf. Prochaska et al., 2012), and 162 individuals reported being previous diagnosed with a mental health disorder. Therefore, 364 four participants were included in final analyses. Seven hundred and ten individuals were removed from data analysis due to incomplete data and ineligibility of a mental health disorder diagnosis. Participant age ranged from 18 to 62 years old, with a mean age of 21.78 years old $(S D=5.39)$. Of the 364 participants, $19.1 \%$ were freshmen; $12.6 \%$ were sophomores; $18.6 \%$ were juniors; $22.2 \%$ were seniors; $13.7 \%$ were graduate students; and $2.4 \%$ of participants defined their non-traditional student status in their own words. Six participants identified as international students; all were acceptably fluent in the English language.

Regarding the racial and/or ethnic identity of the participants, 339 participants indicated identifying with one racial and/or ethnic identity: Asian (2.47\%), Black/African American (3.02\%), Hispanic/Latinx (6.31\%), Pacific Islander (0.27\%), and White/Caucasian (80.77\%).

Twenty five participants identified with multiple racial and/or ethnic identities: Hispanic/Latinx (o/a) and White/Caucasian (1.64\%); Asian and White/Caucasian (1.10\%); Native American/Indigenous Person and White/Caucasian (1.10\%); Middle Eastern and White/Caucasian (0.82\%); Black/African American and White/Caucasian (0.27\%); and Hispanic/Latinx and Pacific Islander (0.27\%); Hispanic/Latinx, Native American/Indigenous Person, and White/Caucasian (0.55\%); Asian, Native American/Indigenous Person, and White/Caucasian (0.55\%); and Asian, Hispanic/Latinx, Pacific Islander (0.27\%), Some 
participants $(0.55 \%)$ preferred to describe their own racial and/or ethnic identity, with responses that included "European American," and "American".

\section{Descriptive Analyses}

Bivariate correlations are depicted in Table 1, which indicate statistically significant negative correlations between distress and disclosure $(r=-.22, p<.010)$ and distress and positive regard for one's mental illness $(r=-.25, p<.010)$, but positive correlations between distress and identity centrality of one's mental illness $(r=.19, p<.010)$ and distress and selfstigma $(r=.32, p<.010)$. Disclosure showed a statistically significant positive correlation with positive regard $(r=.118, p<.050)$ and a statistically significant negative correlation with selfstigma $(r=-.13, p<.050)$. Disclosure did not show a statistically significant correlation with identity centrality $(r=.083, p>.050)$. Identity centrality and positive regard $(r=.12, p=.050)$ and identity centrality and self-stigma $(r=.289, p<.010)$ were statistically significantly positively correlated. Positive regard showed a statistically significant negative correlation with self-stigma $(r=-.35, p<.010)$.

Table 1

Bivariate Correlations and Descriptive Statistics

\begin{tabular}{|c|c|c|c|c|c|}
\hline $\begin{array}{l}\text { Construct } \\
\text { Variables } \\
\end{array}$ & Distress & Disclosure & $\begin{array}{c}\text { Identity } \\
\text { Centrality }\end{array}$ & $\begin{array}{l}\text { Positive } \\
\text { Regard }\end{array}$ & Self-stigma \\
\hline Distress & 1 & - & - & - & - \\
\hline Disclosure & $-.22 * *$ & 1 & - & - & - \\
\hline Identity Centrality & $.19^{* *}$ & .08 & 1 & - & - \\
\hline Positive Regard & $-.25^{* *}$ & $.12^{*}$ & $.12 *$ & 1 & - \\
\hline Self-stigma & $.32 * *$ & $-.13^{*}$ & $.29^{* *}$ & $-.35 * *$ & 1 \\
\hline Mean (SD) & $\begin{array}{l}11.50 \\
(4.45)\end{array}$ & $35.04(20.20)$ & $4.89(1.50)$ & $5.65(1.32)$ & $3.30(.82)$ \\
\hline Range & $0-24$ & $0-100$ & $1-8.5$ & $1.57-8.80$ & $1.10-5$ \\
\hline
\end{tabular}




\section{Main Analyses}

Analyses were conducted to examine empirical relations of Corrigan's (2013) general "out and proud" model, which purports that being "out and proud" about one's mental illness would be linked to reduced self-stigma.

Therefore, the first analyses examined whether disclosing one's mental illness was associated with less self-stigma — assessing the relation between being "out" and one's selfstigma. Results of the regression analyses indicated a statistically significant regression equation, $\left(F(1,362)=5.90, p=.016\right.$, with an $R^{2}=.02, \beta=-0.13$, as shown in Figure 4. For every 1 standard deviation increase in disclosure of one's mental illness, self-stigma decreases 0.13 standard deviations. Those who disclosed their mental illness were shown to have lower levels of mental health self-stigma compared to those who did not disclose.

Figure 4

Original Model of the Relation Between Disclosure and Self-stigma and Supporting Correlation

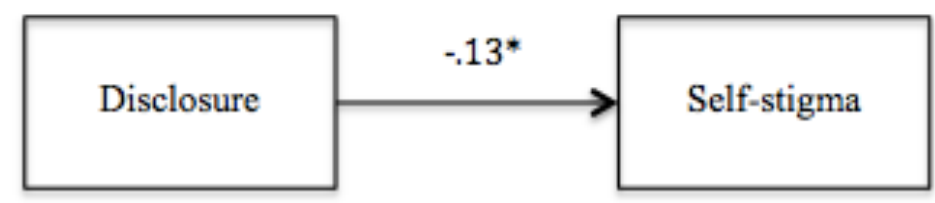

Note: $R^{2}=.02, \beta=-.13, t=-2.43, p=.016$.

$* p<.05$.

Next, the hypothesized model examined both aspects of "out" and "proud" - with disclosure representing one's "outness" and the intersection of identity centrality and positive regard of one's mental illness representing the "proudness". This regression model was shown to be statistically significant, as shown in Figure $5,\left(F(7,356)=5.18, p=.024\right.$, with an $R^{2}=.25$, Disclosure $\beta=-.01$, Identity Centrality $\beta=0.19$, and Positive Regard $\beta=-0.24$. The results show that those who indicated that their mental health diagnosis or psychological distress was 
central to their identity, and had higher positive regard scores were more likely to disclose their mental health diagnosis or psychological distress, thus decreasing their self-stigma.

Figure 5

Hypothesized Moderated Moderation Model

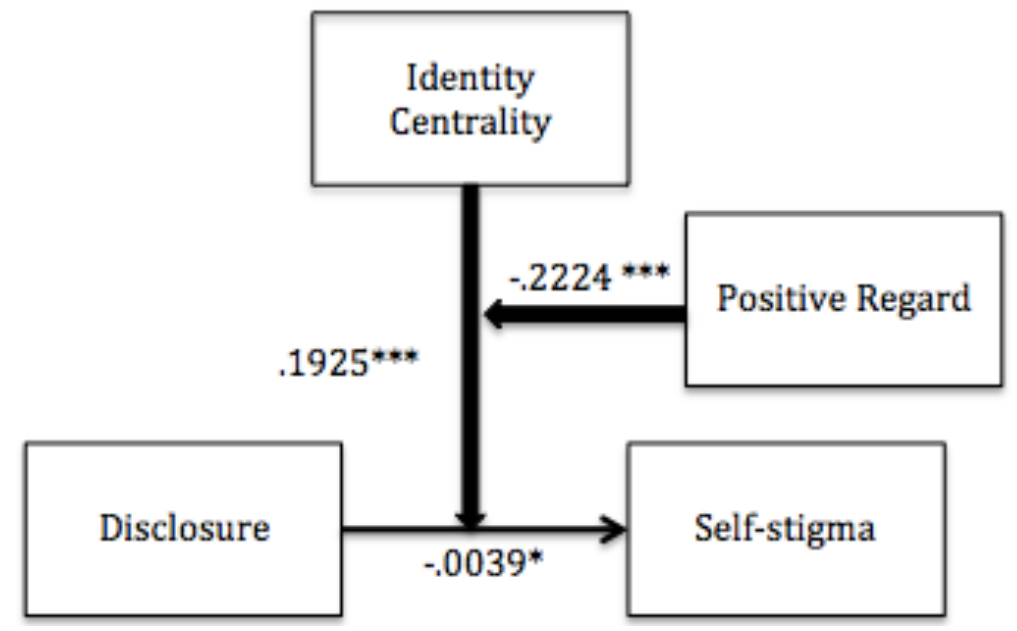

Note: All depicted betas are unstandardized. Thicker lines depict moderating effects, while the thinner line depicts previously supported relation.

$* p<.050 . * * * p<.001$.

Regarding participants who had high positive regard towards their mental health diagnosis or psychological distress and had high identity centrality regarding their diagnosis or distress, those who disclosed less showed higher self-stigma than those who disclosed more, as depicted in Figure 6. These results support my hypothesis that higher scores in identity centrality and higher scores in positive regard, through the relation between disclosure and self-stigma, would ultimately decrease self-stigma, and also supports the concept of "coming out proud."

Further, regarding participants who had low positive regard towards their mental health diagnosis or psychological distress and had low identity centrality regarding their diagnosis or distress, those who disclosed less showed higher self-stigma than those who disclosed more, as depicted in Figure 6. Figure 6 also shows that, regarding participants who had low positive 
regard towards their mental health diagnosis or psychological distress and had high identity centrality regarding their diagnosis or distress, those who disclosed less showed lower selfstigma than those who disclosed more. Interestingly, Figure 6 depicts that those who had low identity centrality and high positive regard reported more self-stigma when they disclosed more. Figure 6

The Hypothesized Moderated Moderation Model's Regression Analysis
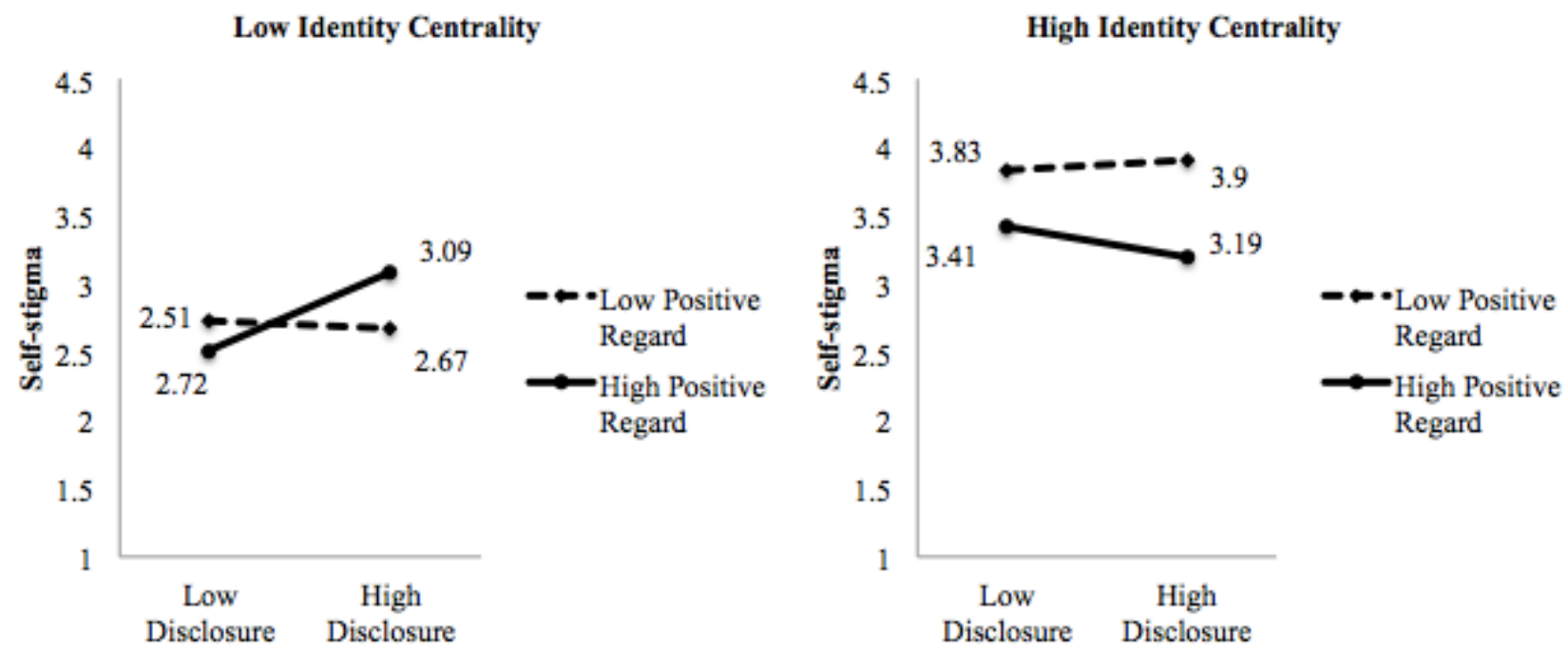

\section{Exploratory Analyses of Minoritized Group Differences}

Results of several Analysis of Variance (ANOVA) tests indicated that there was a statically significant difference in disclosure in regards to racial/ethnic identity, $(F(6,354)=$ $2.54, p=.020)$. Due to an overwhelming majority of participants identifying as singularly White/Caucasian, another analysis was conducted to investigate minoritized status; participants who identified as singularly White/Caucasian were labeled as majoritized, and those who identified as singularly either Asian, Black/African American, Hispanic/Latinx, Pacific Islander, or Middle Eastern. Those who identified with more than one racial and/or identity were labeled as Biracial or Multiracial. Results showed a statistically significant difference regarding 
minoritized status in distress $(F(2,359)=4.61, p=.011)$, disclosure $(F(2,359)=4.49, p=.008)$, and self-stigma $(F(2,357)=4.60, p=.011)$. Table 2 shows the mean differences between these three groups regarding distress, disclosure, identity centrality, positive regard, and self-stigma. It should be noted that those who preferred not to answer were not included in the exploratory analysis or in Table 2.

Table 2

Means and Standard Deviations Across Racial \& Ethnic Identities

\begin{tabular}{cccccc}
\hline Mean(SD) & Distress* $^{*}$ & Disclosure* & $\begin{array}{c}\text { Identity } \\
\text { Centrality }\end{array}$ & $\begin{array}{c}\text { Positive } \\
\text { Regard }\end{array}$ & Self-stigma* \\
\hline $\begin{array}{c}\text { Majoritized } \\
(\text { White/Caucasian) }\end{array}$ & $1.29(0.61)_{a}$ & $36.62(19.55)_{b}$ & $4.89(1.53)$ & $5.71(1.31)$ & $3.25(0.83)_{d}$ \\
$\begin{array}{c}\text { Minoritized } \\
\left(\begin{array}{c}\text { Racial/Ethnic } \\
\text { Identity) }\end{array}\right.\end{array}$ & $1.58(0.50)_{a}$ & $27.56(21.67)_{b, c}$ & $4.96(1.44)$ & $5.57(1.36)$ & $3.64(0.65)_{d}$ \\
$\begin{array}{c}\text { Biracial or } \\
\text { Multiracial }\end{array}$ & $1.40(0.65)$ & $40.89(20.31)_{c}$ & $15.04(1.52)$ & $5.42(1.21)$ & $3.40(0.86)$ \\
\hline
\end{tabular}

Note: Asterisks denote statistically significant mean differences regarding racial/ethnic identities in relation to the variables depicted, while statistically significant mean differences between specific racial/ethnic identities regarding the variables depicted are denoted by the same lowercase letters.

Results indicated that those who identified with one minoritized racial/ethnic identity had higher scores of distress than those who identified as being biracial or multiracial, and those who identified as White, the majoritized racial/ethnic identity. Tukey HSD post hoc analyses showed that only those who identified with one minoritized racial/ethnic identity were statistically significantly different than those who identified as White, $(p=.009)$. Those who identified as biracial or multiracial were not shown to be statistically significantly different from White participants $(p=.659)$ nor participants who identified as one minoritized racial/ethnic identity $(p$ $=.461)$, regarding distress. 
Minoritized individuals were shown to disclose their mental health diagnosis or psychological distress less than those who identified as White and those who identified biracial or multiracial. Those who identified with one minoritized racial/ethnic identity were shown to be statistically significantly different in disclosure compared to participants who identified as White $(p=.013)$ and those who identified as biracial or multiracial $(p=.020)$, according to post hoc analyses. Those who identified as White and those who identified as biracial or multiracial were not shown to be statistically significantly different in regards to disclosure $(p=.557)$.

Finally, self-stigma was shown to be higher for those who identified with one racial or ethnic identity compared to those who identified as biracial or multiracial, who was shown to indicate higher scores of self-stigma than those who identified as White. Tukey HSD post hoc analyses showed that those who identified with one minoritized racial/ethnic identity were statistically significantly different from those who identified as White $(p=.009)$, regarding selfstigma. Those who identified as biracial or multiracial were not shown to be statistically significantly different from those who identified with one racial/ethnic identity $(p=.497)$, nor those who identified as White $(p=.642)$. Identity centrality was not shown to have a statistically significant difference between majoritized individuals, minoritized individuals, or biracial or multiracial individuals $(F(2,359)=0.14, p=.870)$. Positive regard was also not shown to have a statistically significant difference between majoritized individuals, minoritized individuals, or biracial or multiracial individuals $(F(2,358)=0.68, p=.506)$.

Regarding participant gender identity, participants identified as agender (1.92\%), as cisgender men $(15.11 \%)$, as cisgender women $(76.37 \%)$, as gender fluid $(0.55 \%)$, as transgender men $(1.65 \%)$, as transgender women $(0.55 \%)$, preferred not to answer $(1.92 \%)$, or preferred to describe their gender identity in their own words (1.36\%). Initial analyses showed a statistically 
significant difference in positive regard, regarding gender identity, $(F(6,343)=2.917, p=.009)$.

Table 3 shows the statistically significant differences in distress, disclosure, identity centrality, positive regard, and self-stigma. It should be noted that those who preferred not to answer were not included in the exploratory analyses or in Table 3. The use of LGBTQIA+ in Table 3 signifies those who identify as part of the LGBTQIA+ in regards to their gender identity only.

Table 3

Mean Differences Regarding Gender Identity

\begin{tabular}{cccccc}
\hline Mean(SD) & Distress & Disclosure & $\begin{array}{c}\text { Identity } \\
\text { Centrality* }\end{array}$ & $\begin{array}{c}\text { Positive } \\
\text { Regard }\end{array}$ & Self-stigma \\
\hline Cisgender & $1.32(.62)$ & $35.67(20.13)$ & $4.92(1.53)$ & $5.77(1.29)$ & $3.29(.79)$ \\
LGBTQIA+ & $1.55(.51)$ & $36.50(13.43)$ & $5.62(1.70)$ & $5.48(1.20)$ & $3.26(1.04)$ \\
\hline
\end{tabular}

Note: Statistically significant mean differences between cisgender and LGBTQIA+ are denoted by asterisks $(p<.050)$.

Due to the majority of participants identifying as cisgender, further analysis was conducted to combined those who identified as being a part of the LGBQTIA+ community, in terms of gender, as shown in Table 3. Identity centrality was not shown to be statistically significantly in the initial analysis $(F(6,344)=1.174, p=.320)$; however, further analysis showed a statistically significant difference in identity centrality regarding gender identity, $(t(349)=-2.256, p=.025)$. Those who identified as part of the LGBTQIA + community reported higher scores of identity centrality than those who identified as cisgender. Positive regard was not shown to be statistically significant in the further analysis, $(t(348)=0.649, p=.517)$. There were no significant gender differences in initial or further analyses regarding distress $(F(6,344)$ $=.530, p=.785 ; t(349)=-2.678, p=.094)$, disclosure $(F(6,344)=.210, p=.973 ; t(349)=.-$ $151, p=.880)$, or self-stigma $(F(6,342)=1.930, p=.075 ; t(347)=0.271, p=.787)$. 
Following gender identity, participants identified their sexual orientation, which included asexual or demisexual (3.57\%), bisexual (18.96\%), gay or lesbian (5.77\%), straight/heterosexual $(63.74 \%)$, pansexual $(5.22 \%)$, preferred not to answer $(0.55 \%)$, or describing their sexual orientation in their own words $(1.92 \%)$. Initial results showed statistically significant differences in distress $(F(5,355)=2.619, p=.024)$, regarding sexual orientation. Due to the majority of participants identifying as straight/heterosexual, who comprised $63.75 \%$ of the sample, further analysis was conducted by combining those who did not identify as being straight/heterosexual into identifying as being a part of the LGBTQIA+ community, who comprised $35.44 \%$ of the sample, as shown in Table 4. It should be noted that those who preferred not to answer were not included in the exploratory analysis or in Table 4. The use of LGBTQIA+ in Table 4 signifies those who identify as part of the LGBTQIA+ in regards to their sexual orientation only.

Table 4

Mean Differences Regarding Sexual Orientation

\begin{tabular}{cccccc}
\hline Mean(SD) & Distress* & Disclosure* & $\begin{array}{c}\text { Identity } \\
\text { Centrality* }\end{array}$ & $\begin{array}{c}\text { Positive } \\
\text { Regard }\end{array}$ & Self-stigma \\
\hline $\begin{array}{c}\text { Straight/ } \\
\text { Heterosexual }\end{array}$ & $1.25(.63)$ & $34.15(20.89)$ & $4.82(1.49)$ & $5.71(1.34)$ & $3.27(.80)$ \\
LGBTQIA+ & $1.48(.55)$ & $38.48(17.91)$ & & & \\
& & & $5.11(1.51)$ & $5.58(1.25)$ & $3.39(.85)$ \\
\hline
\end{tabular}

Note: Statistically significant mean differences between cisgender and LGBTQIA+ are denoted by asterisks $(p<.05)$.

Distress was still shown to be highly statistically significantly different between the two groups, $(t(348)=-3.16, p=.002)$. Those who identified as part of the LGBTQIA+ community reported more distress than those who identified as straight/heterosexual. Further, disclosure was shown to be statistically significantly different regarding sexual orientation in the further analysis, $(F(1,348)=-1.99, p=.048)$; those who identified as part of the LGBTQIA+ community reported disclosing their mental illness more than those who identified as 
straight/heterosexual. Identity centrality was statistically significantly different regarding sexual orientation in the further analysis, $t(348)=-2.01, p=.046$. There were no significant differences regarding sexual orientation in the initial analysis, nor the further analysis in positive regard $(F(5,354)=1.66, p=.143 ; t(347)=0.47, p=.641)$, or self-stigma $(F(5,353)=2.05, p=.071$; $t(346)-1.31, p=.191)$.

To incorporate participants' identity intersectionality, participant identities were coded 0 - 4, wherein $0=$ majoritized identity (cisgender, straight/heterosexual, White individual), $1=$ one minoritized identity (either being in the LGBTQIA+ community for gender or sexual orientation, or racial/ethnic identity, and 2 and 3 indicated two or three minoritized identities, respectively. I coded the racial/ethnic identity as one minoritized identity, gender identity as another minoritized identity, and sexual orientation being the third possible minoritized identity. Those who identified as being biracial or multiracial were not counted as multiple intersecting identities for this analysis. Four was used to code those who did not indicate identifying with any identity and were not included in the analysis.

Analysis showed that there was a statistically significant difference regarding distress, $(F(3,359)=7.56, p<.001)$. Majoritized individuals indicated lower scores on the Distress Scale than those who identified with one minoritized identity; Tukey HSD post hoc analyses showed that majoritized individuals and those who identified with one minoritized identity were statistically significantly different regarding distress, $(p<.001)$. Majoritized individuals indicated lower scores on the Distress Scale than those who identified with two minoritized identities, which was supported by post hoc analyses $(p=.013)$. Though it is shown that majoritized individuals reported lower distress compared to those who identified as three minoritized identities, the two groups were not shown to be statistically significantly different, $(p$ 
$=.252$ ). Those who identified with one minoritized identity were not shown to be statistically significantly different from those who identified with two minoritized identities $(p=.978)$, nor those who identified with three minoritized identities $(p=.788)$. Those identifying with two minoritized identities were not statistically significantly different than those who identified with three minoritized identities $(p=.872)$.

A statistically significant difference was also found for self-stigma, $(F(3,357)=3.80, p=$ .011). Majoritized individuals reported lower scores of self-stigma than those who identified with one minoritized identity, which was shown to be a statistically significantly difference, ( $p=$ .005). Majoritized individuals reported lower scores of self-stigma than those who identified with two minoritized identities $(p=.816)$ and those who identified with three minoritized identities ( $p$ $=.866)$; however, these were not statistically significant differences. Those who identified with two minoritized identities reported lower scores of self-stigma than those who identified with one minoritized identity $(p=.599)$ or three minoritized identities $(p=.979)$, but these were not shown to be statistically significant, according to the post hoc analyses. Those who identified with one minoritized identity scored slightly higher than those who identified as three minoritized identities, but this difference was not shown to be statistically significant $(p=1.000)$. These results indicate that majoritized individuals experience less psychological distress than those who identify with either one, or more, minoritized identities. Psychological distress was shown to increase for those who identify with multiple minoritized identities. Further, selfstigma was shown to be lower for majoritized individuals, and higher for minoritized individuals, as shown in Table 5. There were no statistically significant differences found regarding intersectionalities for disclosure $(F(3,359)=0.49, p=.687)$, identity centrality $(F(3,359)=$ $2.09, p=.101)$, or positive regard $(F(3,358)=1.50, p=.215)$. 
Table 5

Mean Differences Regarding Identity Intersectionality

\begin{tabular}{|c|c|c|c|c|c|}
\hline Mean(SD) & Distress $* * *$ & Disclosure & $\begin{array}{c}\text { Identity } \\
\text { Centrality }\end{array}$ & $\begin{array}{r}\text { Positive } \\
\text { Regard }\end{array}$ & Self-stigma* \\
\hline Majoritized & $1.19(.63)_{a, b}$ & $34.73(20.18)$ & $4.74(1.52)$ & $5.73(1.32)$ & $3.18(.82)_{c}$ \\
\hline $\begin{array}{l}1 \text { Minoritized } \\
\text { Identity }\end{array}$ & $1.47(.55)_{a}$ & $37.34(21.25)$ & $5.03(1.47)$ & $5.61(1.41)$ & $3.49(.77)_{c}$ \\
\hline $\begin{array}{l}2 \text { Minoritized } \\
\text { Identities }\end{array}$ & $1.51(.56)_{b}$ & $34.40(15.61)$ & $5.17(1.51)$ & $5.62(.85)$ & $3.31(.84)$ \\
\hline $\begin{array}{c}3 \text { Minoritized } \\
\text { Identities } \\
\end{array}$ & $1.75(.50)$ & $37.08(17.18)$ & $5.97(2.15)$ & $4.39(1.49)$ & $3.50(1.54)$ \\
\hline \multicolumn{6}{|c|}{$\begin{array}{l}\text { Note: Statistically significant mean differences regarding racial/ethnic identities in relation to the } \\
\text { variables depicted denoted by asterisks, while statistically significant mean differences between } \\
\text { specific racial/ethnic identities regarding the variables depicted are denotes by the same } \\
\text { lowercase letters. } \\
{ }^{*} p<.050 . * * p<.001 \text {. }\end{array}$} \\
\hline
\end{tabular}




\section{CHAPTER IV: DISCUSSION}

The concept of "coming out proud," proposed by Corrigan (2013) emphasizes that having pride or positive affect towards one's mental illness, accompanied by the action of disclosing one's mental illness to another individual, can decrease stigma associated with one's mental illness. I hypothesized that positive regard moderates the influence that identity, specifically how central a mental health diagnosis is to individuals' identity, moderates the relation between disclosing a mental illness and reported self-stigma. Corrigan's idea of "coming out proud" translates to disclosure and positive regard. Positive regard influences disclosure and self-stigma, but as a moderation to how close one identifies with mental illness, not by itself. Corrigan's model suggests that disclosing one's mental illness may have psychological benefits, but only when one is proud about aspects of their identity related to their mental illness (Corrigan et al., 2010). Therefore, the present study operationalized and tested this theoretical notion. First, the present study examined the relation between self-disclosure of one's mental illness with selfstigma of mental illness. It was hypothesized that an increase in self-disclosure would result in a decrease in self-stigma. The hypothesis was supported as results indicated that an increase in disclosure leads to a decrease in self-stigma. This supports the notion that disclosing one's mental health diagnosis, on average, decreases one's internalized self-stigma.

The present study also tested Corrigan's (2013) “out and proud” model via a moderated moderation model wherein individuals' previous self-disclosure of mental illness predicted selfstigma, but self-disclosure was moderated by their positive regard toward their mental illness as well as the centrality of their mental illness to their identity. It was hypothesized that disclosing one's mental illness would decrease one's self-stigma when one viewed his mental illness as

central to his identity and held positive regard towards it. It was also hypothesized that disclosing 
one's mental illness while holding the diagnosis close to one's identity but not holding positive regard towards the diagnosis would result in an increase in self-stigma. Results support the hypothesis as disclosing with high identity centrality and high positive regard lead to a decrease in self-stigma, however an increase in self-stigma was found if the participant did not report high positive regard towards the diagnosis. In other words, identifying with those who cope with mental illness or holding the mental illness close to one's identity and feeling positively about it results in a decrease in self-stigma when one chooses to disclose one's mental health diagnosis to another. It can be inferred, however, that the attitude towards mental health and mental illness affects the decision to disclose one's mental illness more than how central the diagnosis is to one's identity, as identity centrality was not shown to be as statistically significant as initially anticipated. Positive regard was statistically significantly correlated to distress, disclosure, identity centrality, and self-stigma, but identity centrality was statistically significantly correlated to distress, positive regard, and self-stigma, but not disclosure.

As explored previously, individuals can show high positive regard for their mental illness but if they do not identify with the diagnosis, positive regard may be more apt in investigating the influence of public stigma onto self-stigma. Therefore, identity centrality is a critical component of this study's proposed model. The results show that identity centrality and positive regard towards one's mental illness increases the likelihood for an individual to disclose their mental illness, thus decreasing their self-stigma. Therefore, identity and affect towards one's identity influence how an individual expresses that identity, particularly his mental illness. Identity centrality's significant influence on the relation between disclosure and self-stigma suggests that holding one's mental illness more central to one's identity, if the individual holds high positive regard for the diagnosis, increases the likelihood of disclosing. However, it also 
suggests that holding one's mental illness close to one's identity with low positive regard results in minimal likelihood to disclose, thus increasing one's self-stigma.

It was hypothesized that identity centrality would influence the relation between disclosure and mental health self-stigma, when positive regard moderates identity centrality's influence. The more central individuals perceive their mental illness to be to their identities, with having a positive attitude towards it, the less self-stigma individuals will report when they disclose their mental illness. However, the more central individuals perceive their mental health diagnosis to be to their identities, with having low positive regard, or a more negative attitude towards it, the more self-stigma they will report when they disclose their mental health diagnosis, if they choose to disclose at all.

Regression analyses showed that an increase in identity centrality resulted in a decrease in self-stigma, as individuals chose to disclose their mental health diagnosis, only when positive regard was high. When positive regard was low, an increase in identity centrality resulted in an increase in self-stigma when individuals chose to disclose their mental illness, if they chose to disclose at all. Those who disclosed their mental illness showed an overall decrease in selfstigma. Identity centrality was shown to have a statistically significant positive relation with selfstigma, meaning that the more central a mental illness was to individual's identities, the more self-stigma they would report, unless they held high positive regard; therefore Corrigan's concept of "coming out proud" was supported, as well as the proposed hypotheses.

It may not solely be the act of disclosing that alleviates one's self-stigma, but the complex interplay of the different domains of one's life that influence one's perception of who one is, and how one feels about those domains. Disclosure was negatively correlated with psychological distress and self-stigma, but was positively correlated with positive regard. Both 
the statistically significant correlations and statistically significant moderated moderation model support past and present research suggesting disclosure, positive regard, and identity are imperative to understanding self-stigma and to understanding how to decrease self-stigma.

\section{Mental Health Stigma and Minoritized Groups}

Analyses showed that self-stigma was lower for those who identified as White/Caucasian, compared to those who identified as biracial, multiracial, or identified as a person of color. Meaning that minoritized individuals may experience more psychological distress and may be less likely to disclose, as the results support. This supports previous research that states that those who are people of color are more likely to endorse mental health stigma than White individuals (Corrigan \& Watson, 2007). Those who identified as being a part of the LGBTQIA+ community, regarding gender identity, reported less identity centrality regarding mental health diagnoses and psychological distress, further supporting the conclusion that those who are frequently discriminated against or considered minoritized may be more likely to cope with mental illness or mental health concerns. Overall, it was shown that minoritized individuals experienced more psychological distress and higher self-stigma.

It was shown that those who identified as a part of the LGBQTIA+ community, regarding gender identity, were more likely to perceive their mental illness as more central to their identity, compared to those who identified as cisgender. Further, those who identify as a part of the LGBTQIA+, regarding their sexual orientation, were also shown to hold their mental illness close to their identity, were more likely to disclose, and reported higher distress, when compared to those who identify a straight/heterosexual. These results are supported by previous research, which concludes that those who identify as part of the LGBTQIA+ community are more likely to cope with mental illness or mental health concerns (Plöderl \& Tremblay, 2015). Investigating 
how gender identity and sexual orientation influence the disclosure process, a potential path for future researchers could include how the process of coming out regarding one's sexual orientation and/or gender identity is similar or dissimilar to the disclosure process of mental illness. Those who identify as part of the LGBTQIA+ community have paved the way of coming out research, and understanding the intrapersonal processes that influence the decision to disclose one's gender identity or sexual orientation can benefit the mental health stigma research field.

People who identify with minoritized identities and those who's identities have intersectionalities may benefit more from disclosing their mental illness more so than their majoritized counterparts. Intersectionalities of various minoritized identities are also a direction for future researchers. How intersectionality and the combination of different cultural norms can influence how an individual's invisible identities are perceived in their public circles. It has been found that differing identities can result in differing attitudes towards oneself depending on the environment one is in (Settles, 2004). For example, if one of the individual's cultural groups is accepting or understanding towards his mental illness, that does not necessarily indicate that another one of the individual's cultural groups will also accept or understanding his mental illness. The interaction of identities is imperative to the proposed model.

\section{Implications}

Setti and colleagues (2019) investigated an anti-stigma campaign by incorporating "coming out proud" initiatives, which included three two hour classes on the benefits of coming out about one's mental illness. After the intervention, researchers found that more participants were willing to talk about their mental illness to another person. Researchers also found a decrease in self-stigma after the coming out proud intervention, but they found an increase in 
perceived discrimination. Future research can investigate the aftermath of coming out proud in terms of public stigma, as it has been shown that public stigma influences self-stigma (Vogel et al., 2013). Disclosure may decrease self-stigma and increase self-esteem regarding individuals' mental illness, but it, in turn, may expose them to more discrimination and prejudice from others. Therefore, anti-stigma campaigns and initiatives should still promote coming out proud, but also include information about potential backlash from others and ways to react and cope with it. (Ozeren, 2014). The exploratory analysis along with Setti and colleagues' (2019) results support Corrigan's proposed model that positive regard, or pride, is essential to alleviating self-stigma. The influence of identity centrality to the hypothesized moderated moderation model illuminates the importance of understanding how the complexities that exists in individual people and how they identify and feel about different identities and characteristics. Different people with different environments and different interactions may influence how, when, and why someone chooses to come out proud. Knowing that a complex concept such as identity can show the psychological, more specifically the clinical-counseling community, how important self-concept and self-esteem is to mental health and mental illness.

On the other side of the same coin, existing self-stigma may influence the likelihood of future disclosure; this relation may also be emphasized by identity centrality and positive regard. Results possibly indicate that self-stigma influences disclosure tendencies, whether an individual chooses to disclose or if they chose to conceal their mental illness. An increase in self-stigma may lead to less disclosure from those who cope with mental illness. Public stigma can also influence the likelihood of disclosure due to self-stigma being related to public stigma. Finding an increase in perceived discrimination is related to public stigma, where those who are around individuals who cope with mental illness hold negative and prejudicial views towards them. 
Disclosure thus may not be beneficial for those who are publically ridiculed for their mental illness or who are at risk of overt discrimination (i.e. being terminated from their job, marginalized from their place of worship, etc.). Further, the results show that disclosure was less effective, as it was shown to increase self-stigma for those who reported low identity centrality and low positive regard. Disclosing may be beneficial for those who hold the diagnosis close to their identity, but only when high positive regard is also reported.

Therefore, positive regard alone may not be the only factor that can simultaneously negate the effects of both self-stigma and public stigma. Holding the diagnosis closer to one's identity may provide the individual with a more solidified foundation of self, potentially resulting in a decreased negative response of prejudice from others. Having a strong sense of self has been found to decrease the negative impact of negative events (Alessandri, Perinelli, De Longis, Rosa, Theodorou, \& Borgogni, 2017).

Having a strong sense of self, identity, and having a positive affect towards one's mental illness can help protect oneself from others' discrimination and lasting emotional effects of prejudice (Świtaj, Grygiel, Chrostek, Nowak, Wciórka, \& Anczewska, 2017). This information can be beneficial for those creating anti-stigma campaigns directed towards those who cope with mental illnesses, as well as for those who do not. Those who do not cope with mental illness may benefit from anti-stigma campaigns due to the humanization of the person who copes with mental illness through his act of disclosing to others in a positive and confident manner. Humans learn from other humans on how to react in areas and regarding ideas we are not familiar with (Bandura \& Walters, 1977), therefore those who do not cope with mental illness can learn from those who do about how to accept and take pride in one's struggles, despite the struggles themselves. For those who do not cope with mental illness, but perhaps know someone who 
does, relaying this information about coming out proud to their loved ones may help decrease hostility, also termed high expressed emotion, from loved ones onto those who cope with mental illness (Brown, 1985). Helping those who interact with those who cope with mental illness more positively and with more empathy could potentially assist in alleviating mental health symptoms as well.

This information can benefit counseling psychologists as they can use this information to proactively use interventions to increase the self-esteem of their clients by increasing the positive affect towards and the identity centrality if the mental illness, thus decreasing self-stigma through the act of disclosure. Clinically, these results suggest that when conducting psychotherapy with clients, conversing with the client about their identity and how mental health and mental illness impacts their self-perception can positively impact them and further their recovery, and decrease their mental illness symptoms. It has been shown that self-esteem and a positive self-image can decrease negative symptoms of various mental health diagnoses (Davis, Kurzban, \& Brekke, 2012). Distress was shown to be negatively associated with positive regard, meaning that the higher positive regard an individual has for his mental illness, the less distress he will experience. When a psychotherapist addresses a client's symptomology, decreasing distress is a primary goal, and due to mental health and mental illness being stigmatized in this country, the very diagnosis can be a source of distress (Ben-Zeev, Young, \& Corrigan, 2010). Future directions can investigate if decreasing the distress from the diagnosis, itself, can improve a client's quality of life.

The present study's findings illuminate the need for mental health professionals to learn more about mental health stigma and how to avoid reinforcing internalized self-stigma in those who cope with mental illness. Not only can clinical and counseling psychologists use this 
information while working with clients on understanding and accepting their mental health diagnosis, but it can also be brought to the public, as public stigma influences self-stigma (Vogel et al., 2013). This supports the need to incorporate identity and positive regard into anti-stigma campaigns, directed towards those who cope with mental illness, as well as loved ones of those who cope with mental illness. The act of disclosing with high positive regard and high identity centrality, regardless of the diagnosis, decreases self-stigma. Thus, tailoring anti-stigma campaigns to certain disorders is unnecessary, according to this study's results. Incorporating identity cannot only encourage introspection and reflection in those who cope with mental illness, but it can humanize those who cope with mental illness and normalize being diagnosed with a mental illness, thus decreasing its taboo nature.

The fear of being diagnosed with a mental illness and the expectation of receiving public stigma is a popular concern regarding the decision-making process of those who are concerned with their mental health (Seamark \& Gabriel, 2015). Fear of experiencing public stigma is a barrier to seeking professional psychological services to address one's mental health concerns; the delay can impact the severity of the mental health symptoms, potentially allowing them to worsen over time, if not addressed. Reducing the fear of being diagnosed with a mental illness can remove internal barriers of help-seeking behaviors. One way to reduce this fear may the disclosure of others; the more disclosure from the community may normalize the existence of mental illness and mental health concerns and may humanize the individuals who cope with them in the process. Being "out and proud" may benefit the public and decrease public stigma if receiving a mental health diagnosis is normalized in society.

Regarding those who identify as being part of minoritized groups, results showed that those who have at least one minoritized identity, or more, were more likely to report being 
psychologically distressed and report more self-stigma than those who are majoritized. The hypothesized moderated moderation model's statistical significance can be emphasized when implementing anti-stigma campaigns in areas where there is a large percent of those who identify as being part of minoritized groups living there. Encouraging coming out proud in these neighborhoods and at local community mental health centers can address the higher distress and higher self-stigma of those who identify with one or more minoritized identities.

\section{Limitations and Future Directions}

This study's results support previous hypothesized models concerning the relation between disclosure and mental health stigma, as well as provide support for further research concerning mental health stigma campaigns and clinically relevant interventions regarding cognitive processing of receiving a mental health diagnosis. However, predicting the direction of the moderated moderation model is in question. The hypothesized direction of the moderated moderation model is due to perspective and statistical interpretation. Future research is encouraged to attempt to replicate these findings and to investigate how existing self-stigma interacts with identity centrality and positive regard and how that influences the likelihood of an individual disclosing his mental illness in the future.

This study cannot be generalized to a large variety of individuals, due to a lack of diversity in the sample. The average participant in the present study was approximately 22 years old; however, mental health concerns can occur at any stage of life. There are potential generational differences regarding the act of disclosing a psychological concern to peers. Those of younger generations may be more likely to disclose their mental health diagnosis due to the influence of the LGBTQIA+ community paving the way for "coming out" about invisible identities. Further, everyone in the sample was enrolled in a university course at Illinois State 
University. This sample thus cannot be generalized to those who have not continued their education postsecondary schooling.

Regarding postsecondary schooling, it is shown that those who pursue higher education are more likely to identity as middle or upper socio-economic status (Titus, 2006). This can be for numerous reasons, including the increasing financial burden of families who help their children attend university and institutional racism. Racial diversity in this sample was also low, and therefore the results cannot be generalized to all of those who identify as a person of color, biracial, or multiracial. $80.77 \%$ of participants identified as White/Caucasian, overrepresenting White individuals who cope with mental illness. People of color were underrepresented in this study, as were international students and undocumented permanent residents.

Furthermore, due to the overrepresentation of cisgender women, this study is more generalizable to other cisgender women, then those a part of the LGBTQIA+ community and cisgender men. Differing social norms for those who are a part of the LGBTQIA+ community exist, as do heteronormative expectations of cisgender men (Pool, Schwegler, Theodore, \& Fuchs, 2006). Regarding sexual orientation, straight/heterosexual individuals were also overrepresented, compared to those a part of the LGBGTQIA+ community. Despite sexual orientation being more diverse than gender identity and racial/ethnic identity, this study was still comprised of mostly White/Caucasian, straight/heterosexual, cisgender women.

Different intersectionalities may be qualitatively different from one another and those who identify with intersectionalities in their identities may experience unique discrimination and psychological distress; however, there is no quantitative instrument, to my knowledge, that measures which identities tend to experience more psychological distress or which identities are of the most salient. Some identities may be of upmost importance and very central to their 
identity, but rarely considered for others. The lack of standardization in intersectionalities poses numerous questions regarding the analysis of intersectionalities. Identities may be more central to one person's identity than others; different identities may interact differently with each other. Further, intersectionality is not necessarily the amount of intersection identities, but can be viewed more accurately through the nature of the identities. Qualitative and quantitative research is essential to understanding how intersectionality affects different aspects of one's identity and one's life.

Another limitation of this study was that many participants missed at least one or more attention checks, which could potentially damage the study's validity in their participants' responses. Multiple participants also did not answer every question, also potentially skewing the data. However, despite inconsistency in some responses, most responses were statistically valid and internally consistent, as the reliability statistical results show regarding each scale. Finally, the study's power analysis indicated that a conservative estimate that would achieve a critical F value of 2.02 was a sample size of 725 , while, although this study achieved its goal of obtaining 200 participant responses, the sample size was 364 , only half of the conservative estimate. Increasing the participant responses would potentially include more people of color and more people identifying as a part of the LGBTQIA+ community, which could make the study's results more generalizable to the general public.

Further research is encouraged to take into consideration the previously described limitations of this study. Researchers are encouraged to investigate the potential racial/ethnic and cultural differences of the perception of mental illness and psychological distress, as well as the relation between disclosure and self-stigma. Furthermore, those who identify as being a part of the LGBTQIA+ community, regarding gender identity, were underrepresented in this sample as 
well; these demographics do not reflect those of the general population (Duffin, 2019). This study did not investigate cultural differences in depth; international student status was asked, but only six individuals identified as being international students, however their countries of origin was not asked. Immigrant status was also not asked of participants. Cross-cultural research regarding mental health stigma and disclosure is also encouraged for future researchers. It has been shown that mental illness and the perception of mental health concerns differ crossculturally; therefore, further research is needed to investigate the disclosure process of immigrants, international students, and those who reside in different countries and cultures around the world. Extending cultural research regarding mental health stigma and disclosure can include constructs like religion and spirituality, as it has been shown in prior research that religiosity affects how individuals perceive mental illness, as well as its origins and treatments (Cinnirella \& Loewenthal, 2011).

Environment and family dynamics are also imperative to the act of disclosure; for example, there may be differences in how individuals react to mental illness in rural areas compared to urban areas, alone with differences in available mental health resources. An individual's family experience with mental illness can either encourage or deter him from disclosing or seeking psychological help. Future research is encouraged to investigate family history of mental illness and how it relates to an individual's self-stigma and disclosure tendencies.

It has been shown that different mental health diagnoses carry different connotations. For example, a diagnosis of schizophrenia is often perceived more negatively than a diagnosis of major depression (Wood, Birtel, Alsawy, Pyle, \& Morrison, 2014). How the public perceives the diagnosis may impact the outcome of the disclosure. Infrequently diagnosed conditions, such as 
obsessive-compulsive disorder (OCD), schizophrenia, and personality disorders, and their public connotation may be more difficult to disclose, thus increasing perceptions of self-stigma. Future research can investigate if identity centrality and positive regard's influence is different depending on the mental health diagnosis. More chronic mental health concerns may tend to be incorporated into one's identity compared to single-episode mental health concerns. Examining different disclosure tendencies in a variety of mental health diagnoses may be an important step in developing individuated intervention strategies.

\section{Conclusion}

The results of the present study provide empirical support for the notion that psychological processes related to "coming out proud" buffer against the self-stigmatizing that can occur when one considers their mental illness. Disclosing one's mental illness is linked to lower self-stigma, particularly when one is proud of aspects of their identity related to the mental health concern. Interestingly, when people consider their mental illness as more central to their identity, their self-stigma tends to be higher, but disclosing their mental illness may be a moderating factor that can buffer against that tendency. Specifically, those who held their mental illness more central to their identity but did not hold high positive regard towards the diagnosis were less likely to disclose their mental illness; but when they did disclose, they reported lower self-stigma. Anti-stigma initiatives may consider this when designing anti-stigma curriculum that directly addresses the internal feelings and perceptions of those who cope with mental illness. Coming out proud may be an important beginning for improving the quality of life for those who cope with mental illness. Together, understanding mental health stigma and educating others on this topic can provide support for people coping with mental health concerns and mental illness. 


\section{REFERENCES}

Alessandri, G., Perinelli, E., De Longis, E., Rosa, V., Theodorou, A., \& Borgogni, L. (2017). The costly burden of an inauthentic self: insecure self-esteem predisposes to emotional exhaustion by increasing reactivity to negative events. Anxiety, Stress, \& Coping, 30(6), 630-646. doi: 10.1080/10615806.2016.1262357

Alonso, J. et al. (2008). Association of perceived stigma and mood and anxiety disorders: results from the world mental health surveys. ACTA Psychiatrica Scandinavica, 118, 305-314. doi: 10.1111/j.1600-0447.2008.01241.x

Bandura, A. (1971). Social Learning Theory, New York, NY: General Learning Corporation

Bandura, A., Ross, D., \& Ross, S. A. (1961). Transmission of aggression through the imitation of aggressive models. Journal of Abnormal and Social Psychology, 63, 575-582. doi: $10.1037 / \mathrm{h} 0045925$

Bandura, A., \& Walters, R. H. (1977). Social learning theory (Vol. 1). Englewood Cliffs, NJ: Prentice-hall.

Ben-Zeev, D., Young, M. A., \& Corrigan, P. W. (2010). DSM-V and the stigma of mental illness. Journal of Mental Health, 19(4), 318-327. doi:10.3109/09638237.2010.492383

Boysen, G. A. \& Vogel, D. L. (2008). Education and mental health stigma: the effects of attribution, biased assimilation, and attitude polarization. Journal of Social and Clinical Psychology. 27(5), 447-470. doi: 01.1521/jscp.2008.27.5.447

Brown, G. (1985). The discovery of expressed emotion: induction or deduction? In Expressed Emotion in Families (eds. J. Leff \& C. Vaughn), pp. 7-25. New York: Guilford Press 
Bry, J. L., Mustanski, B., Garofalo, R., \& Burns, M. N. (2017). Management of a concealable stigmatized identity: a qualitative study of concealment, disclosure, and role flexing among young, resilient sexual and gender minority individuals. Journal of Homosexuality, 64(6), 745-769. doi: 10.1080/00918369.2016.1236574

Cinnirella, M., \& Loewenthal, K. M. (2011). Religious and ethnic group influences on beliefs about mental illness: A qualitative interview study. British Journal of Medical Psychology, 72(4). doi: 10.1348/000711299160202

Clark, W., Welch, S. N., Berry, S. H., Collentine, A. M., Collins, R., Lebron, D., \& Shearer, A. L. (2013). California's historical effort to reduce the stigma of mental illness: the mental health services act. American Journal of Public Health. e1-e9. doi:10.2105/AJPH.2013.301225

Corrigan, P. W. (2000). Mental health stigma as social attribution: implications for research methods and attitude change. Clinical Psychology: Science and Practice, 7(1), 48-67. doi: 10.1093/clipsy.7.1.48

Corrigan, P. W. (Ed). (2005). On the stigma of mental illness: practical strategies for research and social change. Washington DC: American Psychological Association.

Corrigan, P.W., \& Watson, A. C. (2007). The stigma of psychiatric disorders and the gender, ethnicity, and education of the perceiver. Community Mental Health Journal, 43, 439458. doi: 10.1007/s10597-007-90840-9

Corrigan, P. W., Larson, J. E., \& Rüsch, N. (2009). Self-stigma and the "why try" effect: impact on life goals and evidence-based practices. World Psychiatry, 8(2), 75-81. doi: 10.1002/j.2051-5545.2009.tb00218.x 
Corrigan et al. (2010). Self-stigma and coming out about one's mental illness. Journal of Community Psychology, 38(3), 259-275. doi:10.1002/jcop.20363

Corrigan, P. W., Kosyluk, K. A., \& Rüsch, N. (2013a). Reducing self-stigma by coming out proud. American Journal of Public Health, 103(5), 794-800. doi: 10.2105/AJPH.2012.301037

Corrigan, P. W., Michaels, P. J., Vega, E., Gause, M., Watson, A. C., Rüsch, N. (2012). Selfstigma of mental illness scale- shot form: Reliability and validity. Psychiatry Research, 199(1), 65-69. doi: 10.1016/j.psychres.2012.04.009

Corrigan, P. W., Sokol, K. A., Rüsch, N. (2013b). The impact of self-stigma and mutual help programs on the quality of life of people with serious mental illnesses. Community Mental Health, 49, 1-6. doi: 10.1007/s10597-011-9445-2

Corrigan, P. W., Michaels, P. J., \& Morris, S. (2015). Do the effects of antistigma programs persist over time? Findings from a meta-analysis. Psychiatric Services, 66(5), 543-546. doi: 10.1176/appi.ps.201400291

Cremonini, V., Pagnucci, N., Giacometti, F., \& Rubbi, I. (2018). Health care professionals attitudes towards mental illness: Observational study performed at a public health facility in northern Italy. Archives of Psychiatric Nursing. 32, 24-30. doi: 10.1016/j.apnu.2017.09.007

Cummings, J. P., Lucas, S. M., \& Druss, B. G. (2013). Addressing public stigma and disparities among persons with mental illness: The role of federal policy. American Journal of Public Health. e1-e5. doi: 10.2105/AJPH.2013.301224 
DeTore, N. R., Hintz, K., Khare, C,. Mueser, K. T. (2019). Disclosure of mental illness to prospective employers: Clinical, psychosocial, and work correlates in persons receiving supported employment. Psychiatry Research, 312-317, doi:

10.1016/j.psychres.2019.01.017

Davis, L., Kurzban, S., \& Brekke, J. (2012). Self-esteem as a mediator of the relationship between role functioning and symptoms for individuals with severe mental illness: A prospective analysis of modified labeling theory, Schizophrenia Research, 137(1-3), 185189. doi: $10.1016 /$ j.schres.2012.02.003

Dietrich, S., Mergl, R., Freudenberg, P, Althaus, D., \& Hegerl, U. (2010). Impact of a campaign on the public's attitudes towards depression. Health Education Research, 25(1), 135-150. doi: $10.1093 /$ her/cyp050

Duffin, Erin. "US Population: Proportion of Woman and Men.” Stastista 9. Aug. 2019, www.statistia.com/statistics/737923/us-population-by-gender/.

Dumesnil, H. \& Verger, P. (2009). Public awareness campaigns about depression and suicide: A review. Psychiatric Services, 60(9), 1203-1213. doi: 10.1176/ps.2009.60.9.1203

Erdfelder, E., Faul, F., \& Buchner, A. (1996). GPOWER: A general power analysis program. Behavior Research Methods, Instruments \& Computers, 28(1), 1-11. doi: 10.3758/BF03203630

Frauenholtz, S., Mendenhall, A. N., \& Moon, J. (2017). Role of school employees' mental health knowledge in interdisciplinary collaborations to support the academic success of students experiencing mental health distress. Children \& Schools, 39(2), 71-79. doi:

$10.1093 / \mathrm{cs} / \mathrm{cdx} 004$ 
Gaebel, W., \& Baumann, A. E. (2003). "Open the doors" - the antistigma program of the world psychiatric association. MMW Fortschr Med., 145(12). 34-37

Hammer, J. H., \& Toland, M. D. (2017). Internal structure and reliability of the internalized stigma of mental illness scale (ISMI-29) and brief versions (ISMI-10, ISMI-9) among Americans with depression. Stigma and Health, 2(3), 159-174, doi: 10.1037/sah0000049

Hayes, A. F. (2017). Introduction to mediation, moderation, and conditional process analysis: a regression-based approach. New York, NY, Guilford Publications

Jorm, A. F. (2015). Why we need the concept of "mental health literacy". Health Communication, 30, 1166-1168. doi: 10.1080/10410236.2015.1037423

Kachanoff, F. J., Ysseldyt, R., Taylor, D. M., de la Sablonniere, R., \& Crush, J. (2016). The good, the bad and the central of group identification: Evidence of a U-shaped quadratic relation between in-group affect and identity centrality. European Journal of Social Psychology, 46, 563-580. doi: 10.1002/ejsp.2199

Kessler, R. C., Andrews, G., Colpe, L. Hiripi, E., Mroczek, D. K., Normand, S.-L., Zaslavsky, A. M. (2002). Short screening scales to monitor population prevalences and trends in nonspecific psychological distress. Psychological Medicine, 32, 959-976. doi: $10.1017 / \mathrm{S} 0033291702006074$

Kessler, R. C., Barker, P. R., Colpe, L. J., Epstein, J. F., Gfroerer, J. C., Hiripi, E., Howes, M. J., Normand, S. T., Manderscheid, R. W., Walters, E. E., \& Zaslavsky, A. M. (2003) Screening for serious mental illness in the general population. Arch Gen Psychiatry, 60(2), 184-189. doi: 10.1001/archpsyc.60.2.184 
Kitchener, B. A., \& Jorm, A. F. (2006). Mental health first aid training: review of evaluation studies. Australian and New Zealand Journal of Psychiatry, 40, 6-8. doi: 10.1080/j.14401614.2006.01735.x

Kopera, M., Suszek, H., Bonar, E., Myszka, M., Gmaj, B., Ilgen, M., \& Wonjnar, M. (2015). Evaluating explicit and implicit stigma of mental illness in mental health professionals and medical students. Community Mental Health, 51, 628-634. doi: 10.1007/s10597-0149796-6

Lally, S. J. (1989). "Does being in here mean there is something wrong with me?". Schizophrenia Bulletin, 15(2), 253-265. doi: 10.1093/schbul/15.2.253

Link, B. G., Cullen, F. T., Struening, E., Shrout, P. E., \& Dohrenwend, B. P. (1989). A modified labeling theory approach to mental disorders: an empirical assessment. American Sociological Review, 400-423. doi: 10.2307/2095613

Lysaker, P. H., Davis, L. W., Warman, D. M., Strasburger, A., \& Beattie, N. (2006). Stigma, social function and symptoms in schizophrenia and schizoaffective disorder: associations cross 6 months. Psychiatry Research, 149, 89-95. doi: 10.1016/j.psychres.2006.03.007

Lysaker, P. H., Roe, D., Yanos, P. T. (2007). Toward understanding the insight paradox: Internalized stigma moderates the association between insight and social functioning, hope, and self-esteem among people with schizophrenia spectrum disorders. Schizophrenia Bulletin, 33(1), 192-199. doi: 10.1093/schbul/sb1016

Mak, W. W. S., Wu, C. F. M. (2006). Cognitive insight and causal attribution in the development of self-stigma among individuals with schizophrenia. Psychiatric Services, 57(12), 18001802. 
Meidlinger, P. C. \& Hope, D. A. (2014). Differentiating disclosure and concealment in measurement of outness for sexual minorities: The Nebraska outness scale. Psychology of Sexual Orientation and Gender Diversity, 1(4), 489-497. doi: 10.1037/sgd0000080

Melas, P. A., Tartani, E., Forsner, T., Edhborg, M., \& Forsell, Y. (2013). Mental health literacy about depression and schizophrenia among adolescents in Sweden. European Psychiatry, 28, 404-411. doi: 10.1016/j.europsy.2013.02.002

Mendenhall, A. N., \& Frauenholtz, S. (2013). Mental health literacy: Social work's role in improving public mental health. Social Work, 58(4), 365-368. doi: 10.1093/sw/swt038

Morrow, D. F. (1996). Coming-out issues for adult lesbians: A group intervention. Social Work, 41(6), 647-656. doi: 10.1093/sw/41.6.647

National Institute of Mental Health. (2017, November). Mental Illness. Retrieved from https://www.nimh.nih.gov/health/statistics/mental-illness.shtml

O'Driscoll, C., Heary, C., Hennessy, E., \& McKeague, L. (2012). Explicit and implicit stigma towards peers with mental health problems in childhood and adolescence. The Journal of Child Psychology and Psychiatry, 53(10), 1054-1062. doi:10.1111/j.14697610.2012.02580.x

Omori, A., Tateno, A., Ideno, T., Takahashi, H., Kawashima, Y., Takemura, K., \& Okubo, Y. (2012). Influence of contact with schizophrenia on implicit attitudes towards schizophrenia patients held by clinical residents. BMC Psychiatry, 12(205). doi: 10.1186/1471-244X-12-205 
O'Reilly, C. L., Bell, J. S., Kelly, P. J., \& Chen, T. F. (2011). Impact of mental health first aid training on pharmacy students' knowledge, attitudes and self-reported behavior: A controlled trial. Australian and New Zealand Journal of Psychiatry, 45, 549-557. doi:10.3109/00048674.2011.585454

Ozeren, E. (2014). Sexual orientation discrimination in the workplace: A systematic review of literature, Procedia - Social and Behavioral Sciences, 109, 1203-1215. doi; 10.1016/j.sbspro.2013.12.613

Perry, Y., Petrie, K., Buckley, H., Cavanagh, L., Clarke, D., Winslade, M., Hadzi-Pavlovic, D., Manicavasagar, V., \& Christensen, H. (2014). Effects of a classroom-based educational resource on adolescent mental health literacy: a cluster randomized controlled trial.

Journal of Adolescence, 37, 1143-1151. doi:10.1016/j.adolescence.2014.08.001

Pinto-Foltz, M. D., Logsdon, M. C., \& Myers, J. A. (2011). Feasibility, acceptability, and initial efficacy of a knowledge-contact program to reduce mental illness stigma and improve mental health literacy in adolescents. Social Science \& Medicine, 72, 2011-2019. doi: 10.1016/j.socsimes.2011.04.006

Plöderl, M., \& Tremblay, P. (2015). Mental health of sexual minorities. A systematic review. International Review of Psychiatry, 27(5), 367-385. doi: $10.3109 / 09540261.2015 .1083949$

Pool, G. J., Schwegler, A. F., Theodore, B. R., \& Fuchs, P. N. (2006). Role of gender norms and group identification on hypothetical and experimental pain tolerance. Pain, 129(1-2), 122-129. doi: 10.1016/j.pain.2006.10.008 
Prochaska, J. J., Sung, H., Max, W., Shi, Y., \& Ong, M. (2012). Validity study of the K6 scale as a measure of moderate mental distress based on mental health treatment need and utilization, International Journal of Methods in Psychiatric Research, 21(2), 88-97. doi: 10.1002/mpr.1349

Quinn, D. M., \& Chaudoir, S. R. (2009). Living with a concealable stigmatized identity: The impact of anticipated stigma, centrality, and cultural stigma on psychological distress and health. Journal of Personality and Social Psychology, 97(4), 634-651. doi: $10.1037 / \mathrm{a} 0015815$

Quinn, D. M., Williams, M. K., Quintana, F., Gaskins, J. L., Overstreeet, N. M., Pishori, A., Earnshaw, V. A., Perez, G., Chaudoir, S. R. (2014). Examining effects of anticipated stigma, centrality, salience, internalization, and outness on psychological distress for people with concealable stigmatized identities. PLOS ONE, 9(5), e96977. doi: 10.1371/journal.pone.0096977

Reavley, N. J., \& Jorm, A. F. (2011) Stigmatizing attitudes towards people with mental disorders: findings from an Australian national survey of mental health literacy and stigma. Australian and New Zealand Journal of Psychiatry, 45, 1086-1093. doi: $10.3109 / 00048674.2011 .621061$

Reavely, N. J. \& Jorm, A. F. (2012). Stigmatizing attitudes towards people with mental disorders: Changes in Australia over 8 years. Psychiatry Research, 197, 302-306. doi:10.1016/j.psychres.2012.01.011

Reavely, N. J., McCann, T. V., \& Jorm, A. F. (2012). Mental health literacy in higher education students. Early Intervention in Psychiatry, 6, 45-52. doi: 10.1111/j.17517893.2011.00314.x 
Rudick, C. K., \& Dannels, D. P. (2018). Yes, and...: Continuing the scholarly conversation about mental health stigma in higher education. Communication Education, 67(3). 404408. doi:10.1080/03634523.2018.1467563

Rüsch, N., Angermeyer, M. C., \& Corrigan, P. W. (2005). Mental illness stigma: concepts, consequences, and initiatives to reduce stigma. European Psychiatry, 20, 529-539. doi: 10.1016/j.europsy.2005.04.004

Sartirious, N. (2010). Short-lived campaigns are not enough the stigma of mental illness will be reduced only if region-specific awareness initiatives become a permanent fixture of health and social services. Comment. 468, 163-165. doi: 10.1038/468163a

Schomerus, G., Schwahn, C., Holzinger, A., Corrigan, P. W., Grabe, H. J., Carta, M. G., \& Angermeyer, M. C. (2012). Evolution of public attitudes about mental illness: a systematic review and meta-analysis. Acta Psychaitrica Scandinavica, 125, 440-451. doi: 10.1111/j.1600-0447.2012.01826.x

Seamark, D., \& Gabriel, L. (2018). Barrier to support: A qualitative exploration into the helpseeking and avoidance factors of young adults. British Journal of Guidance \& Counseling, 46(1), 120-131. doi: 10.1080/03069885.2016.1213372

Sebastian, J., \& Richards, D. (2017) Changing stigmatizing attitudes to mental health via education and contact with embodied conversational agents. Computers in Human Behavior, 73, 479-488. doi: 10.1016/j.chb.2017.03.071

Sebastian, J., Richards, D., \& Bilgin, A. (2017). Education and contact strategies to reduce stigmatizing attitudes towards anorexia nervosa among university students. Health Education Journal, 76(8), 906-922. doi: 10.1177/0017896917724181 
Sellers, R. M., Rowley, S. A. J., Chavous, T. M., Shelton, J. N.,\& Smith, M. A. (1997). Multidimensional inventory of Black identity: A preliminary investigation of reliability and construct validity. Journal of Personality and Social Psychology, 73(4), 805-815.

Setti, V. P. C., Loch, A. A., Modelli, A., de Almedia Rocca, C. C., Hungerbuehler, I., van de Bilt, M. T., Gattaz, W. F, \& Rössler, W. (2019). Disclosing the diagnosis of schizophrenia: A pilot study of the 'coming out proud' intervention, International Journal of Social Psychiatry, 1-8. doi: 10.1177/0020764019840057

Settles, I. H. (2004). When multiple identities interfere: The role of identity centrality. Personality and Social Psychology Bulletin, 30(4), 487-500. doi: $10.1177 / 0146167203261885$

Skre, I., Frinborg, O., Breikil, Johnsen, L. I., Arnesen, Y., Wang, C. E. A. (2013). A school intervention for mental health literacy in adolescents: Effects of a non-randomized cluster controlled trial. Public Health, 13, 873. doi: 10.1186/1471-2458-13-873

Smith, R. A. (2007). Language of the lost: An explication of stigma communication. Communication Theory, 17, 462-485. doi:10.1111/j.1468.2885.2007.003707.x

Smith, R. A. \& Applegate, A. (2018). Mental health stigma and communication and their intersections with education. Communication Education. 67(3), 382-393. doi: $10.1080 / 03634523.2018 .1465988$

Stull, L. G., McGrew, J. H., Salyers, M. P., \& Ashburn-Nardo, L. (2013). Implicit and explicit stigma of mental illness attitudes in an evidence-based practice. The Journal of Nervous and Mental Disease, 201(12), 1072-1079. doi: 10.1097/NMD.00000000000000056 
Swartz, K. L., Kastelic, E. A., Hess, S. G., Cox, T. S., Gonzales, L. C., Mink, S. P., \& DePaulo J. R. (2010). The effectiveness of a school-based adolescent depression education program. Health Education \& Behavior, 37(1), 11-22. doi: 10.1177 .1090198107303313

Swartz, K., Musci, R. J., Beaudry, M. B., Heley, K., Miller, L., Alfes, C., Townsend, L., Thornicroft, G., \& Wilcox, H. C. (2017). School-based curriculum to improve depression literacy among US secondary school students: a randomized effectiveness trial. American Journal of Public Health, 107(12), 1970-1976. doi:10.2105/AJPH.2017.304088

Świtaj, P., Grygiel, P., Chrostek, A., Nowak, I., Wciórka, J., \& Anczewska, M. (2017). The relationship between internalized stigma and quality of life among people with mental illness: are self-esteem and sense of coherence sequential mediators? Qual Life Res, 26, 2471-2478. doi: 10.1007/s11136-017-1596-3

Tay, J. L., Tay, Y. F. \& Klainin-Yobas, P. (2018). Mental health literacy levels. Archives of Psychiatric Nursing. 1-7. doi:10.1016.j.apnu.2018.04.007

Thornicroft, G., Mehta, N., Clement, S., Evans-Lacko, S., Doherty, M., Rose, D., Koschorke, M., Shidhaye, R., O'Reilly, C., \& Henderson, C. (2015). Evidence for effective interventions to reduce mental-health-related stigma and discrimination. Lancet, 387, 1123-1132. doi: 10.1016/S0140-6736(15)00298-6

Titus, M. A. (2006). Understanding college degree completion of students with low socioeconomic status: The influence of the institutional financial context. Researcher in High Education, 47(4), 371-398. doi: 10.1007/s11162-005-9000-5

Tucker, J. R., Hammer, J. H., Vogel, D. L., Bitman, R. L., Wade, N. G., \& Maier, E. J. (2013). Disentangling self-stigma: Are metal illness and help-seeking self-stigmas different? Journal of Counseling Psychology, 60(4), 520-531. doi: 10.1037/a0033555 
Villicana, A. J., Delucio, K., \& Biernat, M. (2016). "Coming out" among gay Latino and gay White men: Implications of verbal disclosure for well-being. Self and Identity, 15(4), 468-487. doi: 10.1080/15298868.2016.1156568

Vogel, D. L., Bitman, R. L., Hammer, J. H., \& Wade, N. G. (2013). Is stigma internalized? The longitudinal impact of public stigma on self-stigma. Journal of Counseling Psychology, 60(2), 311-316. doi: 10.1037/a0031889

Vogel, D., Wade, N., Haake, S. (2006). Measuring the self-stigma associated with seeking psychological help. Journal of Counseling Psychology, 53, 325-337. doi:10.1037/00220167.53.3.325

Weisman, H. L., Kia-Keating, M., Lippincott, A., Taylor, Z., \& Zheng, J. (2016). Mental health stigma prevention: Pilot testing a novel, language arts curriculum-based approach for youth. Journal of School Health, 86(10), 709-716. doi: 10.111/josh.12427

Wood, L., Birtel, M., Alsway, S., Pyle, M., Morrison, A. (2014). Public perceptions of stigma towards people with schizophrenia, depression, and anxiety. Psychiatry Research, 22(12), 604-608. doi: 10.1016/j.psychred.2014.07.012

Zhuang, X. Y., Wong, D. F. K., Cheng, C., \& Pan, S. (2017). Mental health literacy, stigma and perception of causation of mental illness among Chinese people in Taiwan. International Journal of Social Psychiatry, 63(6), 498-507. doi: 10.1177/002076-4017719303 